Vitaliy A. Ivanov ${ }^{1}$, Vladimir A. Dulov ${ }^{1 *}$, Sergey Yu. Kuznetsov², Sergey F. Dotsenko' ${ }^{1}$, Mikhail V. Shokurov ${ }^{1}$, Yana V. Saprykina ${ }^{2}$, Vladimir V. Malinovsky ${ }^{1}$, Vladislav G. Polnikov ${ }^{3}$

${ }^{1}$ Marine Hydrophysical Institute, Sevastopol, Ukraine

${ }^{2}$ Institute of Oceanology of P.P. Shirshov, Moscow, Russian Federation

${ }^{3}$ A.M. Obukhov Institute of Atmospheric Physics, Moscow, Russian Federation

*Corresponding Author; e-mail: dulov1952@gmail.com

\title{
RISK ASSESSMENT OF ENCOUNTERING KILLER WAVES IN THE BLACK SEA
}

ABSTRACT. The problem of assessing the risk for a vessel to encounter a killer wave in the Black Sea is considered. Analysis of in situ wave data obtained from the platform of Marine Hydrophysical Institute in the autumn of 2009 shows that occurrence frequency of abnormally high waves (freak, rogue, or killer waves) varies considerably on the time scale of several hours. It is shown that the formation of such waves is associated with nonlinear processes in the wave field, presumably, with the development of modulational instability. Ninety percent of the total number of killer waves was observed in the swell wave system, and $70 \%$ of them propagated approximately in wind direction. We propose a scenario of the killer waves formation in the Black Sea. The scenario was confirmed by numerical reconstruction of the wind and wave fields in the Black Sea for the history of storms on Oct. 14, 2009 in Katsiveli and on Feb. 01, 2003 in Gelendzhik, using the MM5 mesoscale atmospheric model and the WAM-C4 wave model. A practical approach to assessing the risk for a vessel to encounter a killer wave in the Black Sea is presented.

KEY WORDS: storm seas, killer/freak/rogue waves, Benjamin-Feir instability, field study in the Black Sea, numerical recovery of wind and wave fields, risk assessment for extreme maritime events.

\section{INTRODUCTION}

Extreme high sea waves have long been known legends and folklore of many countries. In English literature, the most common names are "freak waves" and "rogue waves", i.e., the unusual, bizarre, wondering waves, which appear "from nowhere", even in the absence of strong wind, and stand out from the surrounding wind waves because of their abnormal height and steepness. In Russian literature, they are called "killer waves". Encounters with killer waves may cause damage or loss of a vessel or life. A description of such incidents is the subject of numerous publications (see e.g., [Kurkin and Pelinovsky, 2004; Dotsenko and Ivanov, 2006; Kharif, et al., 2009]). To date, forecast of occurrence of killer waves and risk assessment of vessels' encounters with killer waves remain pressing problems of environmental safety.

In recent decades, there has been steadily increasing interest in the extremely high waves on the sea surface and, consequently, a growing number of publications on various issues related to killer waves. This is due to recognition of the fact that killer waves are not extremely rare, and they, apparently, can be found in all regions of the world ocean [Kharif, et al., 2009]. Moreover, there is a point of view that, in the future, frequency of encounters with killer waves will increase due to climate change [Osborne, et al., 2005]. In the Black Sea, for the first time, a killer wave was recorded by a wave-monitoring buoy in 2001 near Gelendzhik [Divinsky, et al., 2003]. Since then, the number of instrumental observations of the anomalous high waves in the Black Sea has increased significantly [Kuznetsov, et al, 2006; Dotsenko, et al., 2009, 
2010; Saprykina, et al., 2010; Kuznetsov, et al., 2011].

To date, a number of possible physical mechanisms of the killer wave formation are known. Their detailed description with a broad review of the literature is given in the book by Kharif, Pelinovsky, and Slunyaev [2009]. The most common point of view is that the concentration of wave energy, necessary to form extremely high waves, is the result of wave focusing. There are different types of wave focusing: spatial (geometrical) focusing caused by inhomogeneities of the marine environment, currents, topography, and weather conditions; temporal focusing (or "dispersion compression") associated with nonstationarity of the medium or with a special character of wave generation; and "non-linear focusing" during the development of modulational instability of a homogeneous train of waves, also known as the Benjamin-Feir instability. The possibility of the formation of the abnormally high waves as a result of these mechanisms is confirmed by numerical simulations and in laboratory experiments.

For a "purely" nonlinear mechanism associated with modulational instability, in order for killer waves to form, it is not necessary to have special focusing properties of the marine environment in the form of spatial or temporal inhomogeneities. The efficiency of the nonlinear mechanism is determined by the steepness or the "nonlinearity parameter" of the waves $\varepsilon=$ $=a k$, where $a$ is the amplitude, and $k$ is the wave number. Several authors have given a possible explanation of the killer waves' properties being a result of modulational instability ([Onorato, et al., 2001; Janssen, 2003; Socquet-Juglard, et al., 2005; Chalikov, 2007; Zakharov, et al.,2008], etc.). Under this interpretation, the following theory for the killer wave prediction was proposed [Janssen, 2003; Mori and Janssen, 2006]. The result of this prediction is the probability of wave occurrence with a height $H$ exceeding the significant wave height $H_{5}$ by a specified number of times $n=\mathrm{H}_{\mathrm{H}}$ :

$$
\begin{aligned}
& P_{H}(n)=\exp \left(-2 n^{2}\right) \times \\
& \times\left[1+\left.2 n^{2}\left(n^{2}-1\right) \frac{\pi}{3 \sqrt{3}} B F\right|^{2}\right] .
\end{aligned}
$$

This probability can be calculated using the Benjamin-Feir index (BFI):

$$
B F I=\sqrt{2} \varepsilon f_{p} / \triangle f
$$

where $f_{p}$ is the frequency of the wave spectral peak, $\varepsilon$ and $\Delta f$ is steepness of waves and the width of the frequency spectrum defined, in one way or another, from the wave spectrum.

The wave spectrum can be predicted traditionally using the WAM-models and wind field forecast (see, e.g., [Komen, et al., 1994]). Under this approach and beginning in 2003, the ECMWF (European Center for Medium Range Weather Forecast) has being producing the $\mathrm{BFI}$ among formal parameters of prediction of the probability of extremely dangerous sea waves: if $\mathrm{BFI}$ is close to 1, the situation may be considered hazardous. To date, however, there are apparently no known facts that support the usefulness of such a forecast for the prevention of ship encounters with killer waves (see also extensive discussion of the problem in [Kharif, et al., 2009, pp 162-164]).

Focusing of the wave field by all of the abovementioned physical mechanisms is only effective if a wave is quasimonochromatic, i.e., when the spectrum is narrow enough both in frequency and direction of wave propagation (see, e.g., [Kharif, et al., 2009]). This condition for the width of the spectrum in the frequency domain is shown in Equation (1) for BFI: decrease of $\Delta f$ causes increase of $B F I$ and, accordingly, the probability of occurrence of extremely high waves. However, the condition of a sufficiently small angular width of the spectrum is definitely not the 
case for the well-known empirical models of the wind wave spectra [Onorato, et al., 2009]. Thus, one can expect that modulational instability in the real seas will develop only at a special shape of the wind wave spectrum that differs significantly from what is usually observed. On the other hand, waves of swell coming from a remote area of a storm and not related to local winds have a relatively narrow spectrum. As it follows from (1), the system of swell waves with sufficient steepness would have BFI close to 1 and, thus, could produce killer waves. In the Black Sea, as a rule, there are a system of wind waves and a system (or multiple systems) of swell observed simultaneously. Most often, the system of swell dominates and the waves of the spectrum peak relate specifically to this system.

Professional sailors are well aware of highrisk situations when wind increases in the same direction as the swell. In particular, in such circumstances, the inhabitants of the Crimean coast, for fear of accidents, do not go out to sea on small vessels. Considering the arguments presented above, the following possible explanation of this tradition may be suggested. A collinear wind enhances the swell. Upon swell waves reaching a sufficiently steep slope, modulational instability develops and produces sporadically the abnormally high waves. As a result, the wave situation at sea becomes dangerous.

This scenario is supported by [Tamura, et al., 2009], where a model reconstruction of the wind and wave conditions for the time of the accident in the Kuroshio region has been performed; specifically, a fishing boat with twenty crewmembers sank as a result of an encounter with killer waves. Note also that there are publications discussing the swell effect on occurrence of killer waves in the wind-driven wave system ([Donelan and Magnusson, 2005; Gramstad and Trulsen, 2010], etc.). In these papers, it was assumed that killer waves are unlikely to occur in the swell system due to lack of sufficient steepness of swell waves.
The issues discussed above provide motivation for writing this paper. Its main purpose is to show the applicability of the viewpoint that the formation of killer waves in the Black Sea is mainly the result of modulational instability of swell waves and that a particular danger is associated with the situation when swell waves propagate in the direction of wind. The work is based on the analysis of the experimental data obtained in the joint field experiment of the Marine Hydrophysical Institute of the National Academy of Sciences of Ukraine (MHI) and P.P. Shirshov Institute of Oceanology of the Russian Academy of Sciences (IO) in 2009 [Saprykina, et al., 2010; Kuznetsov, et al., 2011].

The paper is organized to present these data and to consistently answer the following questions: i) whether it is possible to interpret the field observations of anomalously high waves in the Black Sea as the development of modulational instability, ii) whether the abnormally high waves in the Black Sea are associated with swell waves, and iii) whether collinear wind and swell waves lead to the emergence of killer waves. In conclusion, the paper presents a simple procedure of estimating the risk of a ship encountering a killer wave in the Black Sea built on the assumption that all answers to the questions posted above are positive. The procedure may be applied in the practice of navigation.

\section{THE FIELD EXPERIMENT}

The joint field experiments of 10 and MHI [Saprykina, et al., 2010] was carried out from Oct. 12 to Nov. 6, 2009, at the stationary oceanographic platform of the Experimental Department of $\mathrm{MHI}$ (the settlement Katsiveli, the southern coast of Crimea, located at $44^{\circ} 23^{\prime} \mathrm{N} 33^{\circ} 59^{\prime} \mathrm{E}$ ). The photo of the platform and the schematic representation of its location relative to the coastline are shown in Fig. 1. The distance to the nearest coastal point is approximately $0.5 \mathrm{~km}$. The sea depth at the platform location is $28 \mathrm{~m}$. 

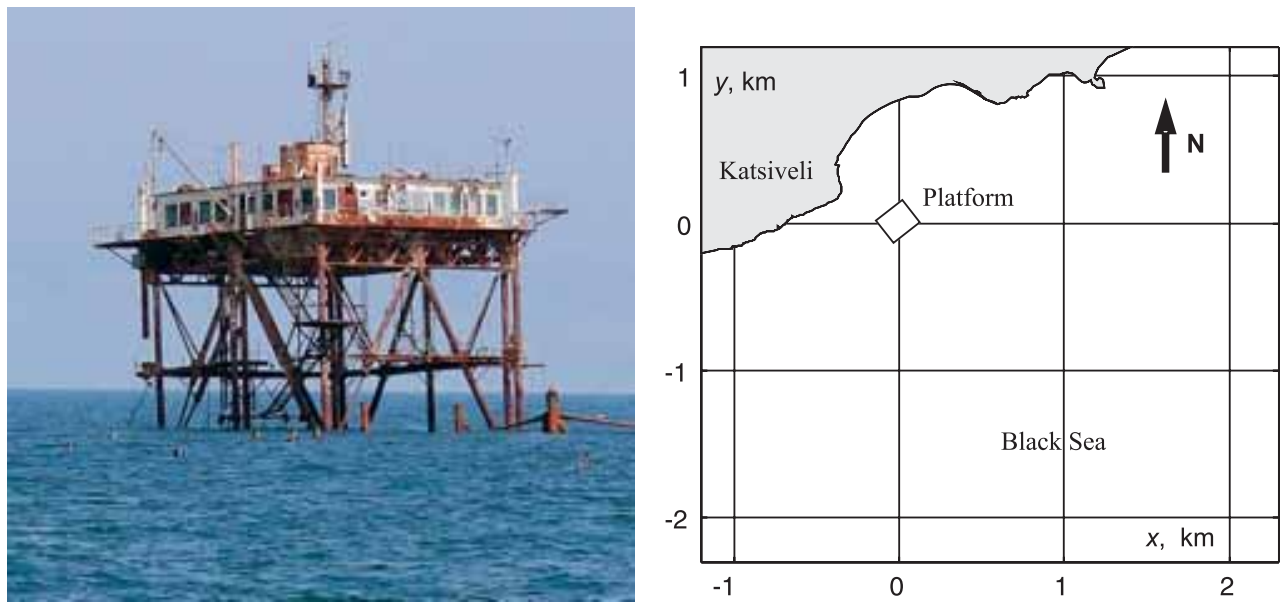

Fig. 1. The research platform of MHI near the settlement Katsiveli. The general view and the layout

For a complete spatial recording of surface waves, two wave gauge arrays (WGAs) were used simultaneously. The "small" WGA was composed of five string resistance sensors located at the vertices of a regular pentagon at a distance of $25 \mathrm{~cm}$ from the center and of one at its center. The whole construction was suspended on a lifting boom at a distance of $10 \mathrm{~m}$ from the nearest platform column. The suspension system allows through-calibration of the measuring by the vertical displacement of the sensors at accurately measured distances. With this well-controlled linearity of the sensor, a fundamentally important property in evaluating characteristics of nonlinear waves was achieved.

The"large"WGAincluded four string capacitive sensors, spaced at distances from 3 to $16 \mathrm{~m}$ in order to increase the angular resolution of the sensor system for the longest surface waves. The "large"WGA operated during Oct. 12-24; the "small" WGA operated through the entire duration of the experiment. Each WGA had its own recording equipment with a sampling frequency of $10 \mathrm{~Hz}$ or greater. Continuous wave recordings were conducted for periods ranging from several hours to several days. In addition, a meteorological complex operated continuously with an autonomous registration system, which recorded meteorological parameters every minute, including wind speed and direction at the horizon of $23 \mathrm{~m}$. In order to avoid false alarms associated with ship waves, only those records where the significant wave height exceeded $0.5 \mathrm{~m}$ were selected for processing. The total length of the records was 217 hours.

To calculate wave characteristics, the data sets were broken down into non-overlapping twenty-minute intervals. For each interval, the maximum wave height $H_{\max }$, the variance $\sigma^{2}=\left\langle\zeta^{2}\right\rangle$, and the fourth central moment $\mu_{4}=\left\langle\zeta^{4}\right\rangle$, where $\zeta$ is the elevation of the sea surface relative to the average level, as well as the significant wave height $H_{S}=40$ and kurtosis of distributions of elevations $K_{t}=\mu_{4} / \sigma^{4}$, which characterizes the intensity of nonlinear interactions in the wave field [Janssen, 2003], were determined.

To identify killer waves in the instrumental records of the surface waves, there are a number of criteria based on the characteristics of individual waves (see, e.g., [Guedes Soares, et al., 2004; Kurkin and Pelinovsky, 2004, Kharif, et al., 2009]). Typically, these definitions are descriptive in nature and not related to the physical mechanisms and conditions of the formation of killer waves. At the same time the results of laboratory studies of killer waves can be extended to natural conditions using dimensional consideration. If period of the waves in an experimental tank is $m$ times less than in natural conditions, then, 
in the transition to the field conditions, all geometric dimensions of the waves must be multiplied by $m^{2}$. This follows from the linear dispersion relation for the surface waves in deep water. It is essential to keep constant the steepness of the waves at the transition, as a parameter that determines the intensity of nonlinear processes. For this reason, the most widely used simple criterion for the selection of killer waves in practice is the height of the abnormally high waves that is two or more times greater than the significant wave height [Kharif, et al., 2009]:

$$
H>2 H_{s}
$$

In this case, the definition of killer waves includes relatively low waves, for example, with a height of about two meters that, in the usual sense, are not dangerous. However, the records of such waves can be used to study physical mechanisms of the formation of real killer waves.

Using criterion (2), 40 abnormally high waves were identified. Fig. 2 shows an example of such a wave. The fact that killer waves are not very rare events is consistent with earlier research (see, e.g., [Liu and Pinho, 2004; Kharif, et al., 2009]). However, the moments of their appearance are clearly not associated with local wind speed and wave height. These points are non-uniformly distributed over time.
Fig. 3 illustrates non-uniformity of frequency of occurrence of killer waves on a timescale of about an hour during the storm in Katsiveli on Oct. 14, 2009. The figure shows wind speed, its direction, and the significant wave height as the functions of time. In addition, frequency of occurrence of anomalous waves $N$, selected according to the criterion (2) for the time interval of one hour and summed over all nine sensors, are shown. In the intervals 04:0008:00 and 09:00-13:30, the anomalous wave heights were observed quite frequently; in the interval 13:30-16:40, they were entirely absent. Variability of $N$ in Fig. 3, obviously, does not follow any changes of wind speed or the significant wave height.

Fig. 4 shows the probability density function (PDF) of elevations of the sea surface from the mean sea level, normalized at $H_{s}$ that was obtained from the combined data of nine sensors for the time-intervals 10:00-11:00 and 13:40-14:40. It also shows the Gaussian curve corresponding to the linear, i.e., non-interacting, waves. As can be seen from the figure, during the time of observation of abnormally high waves, the shape of PDF is very different from the Gaussian. That is in this case, the wave field has clearly nonlinear properties [Janssen, 2003; Onorato, et al., 2009].

Fig. 5 shows dependency of the index of abnormality, $A_{l}=H_{\max } / H_{S}$ [Kharif, et al., 2009],
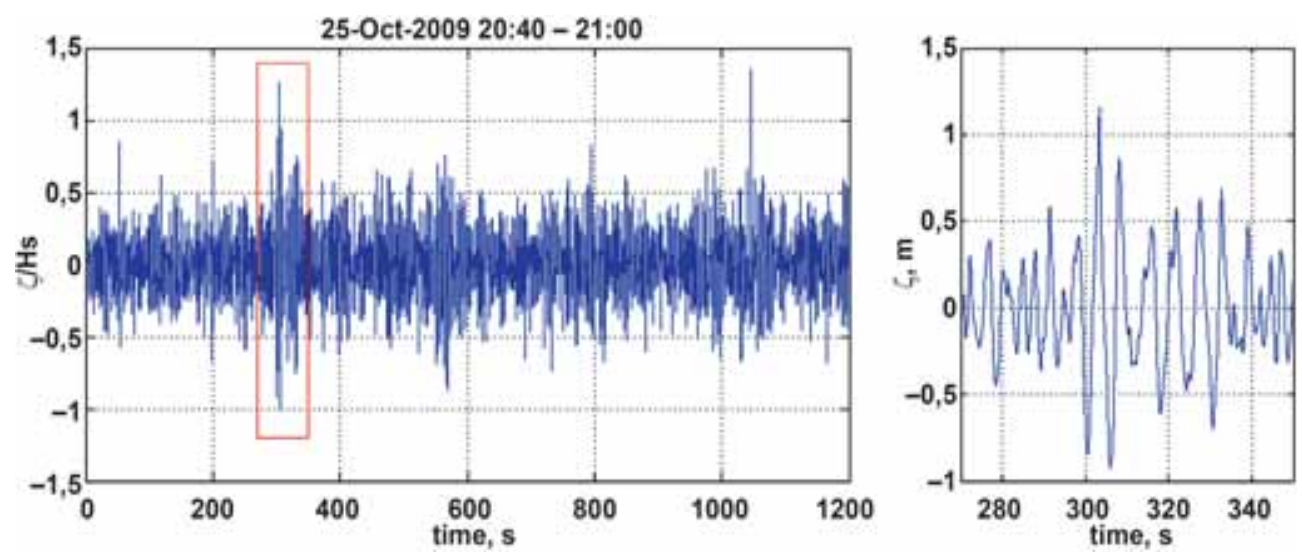

Fig. 2. A fragment of a record of the sea surface elevations containing a wave of the anomalous height. This wave and its neighborhood are marked by the rectangle and are shown, in detail, on the right 

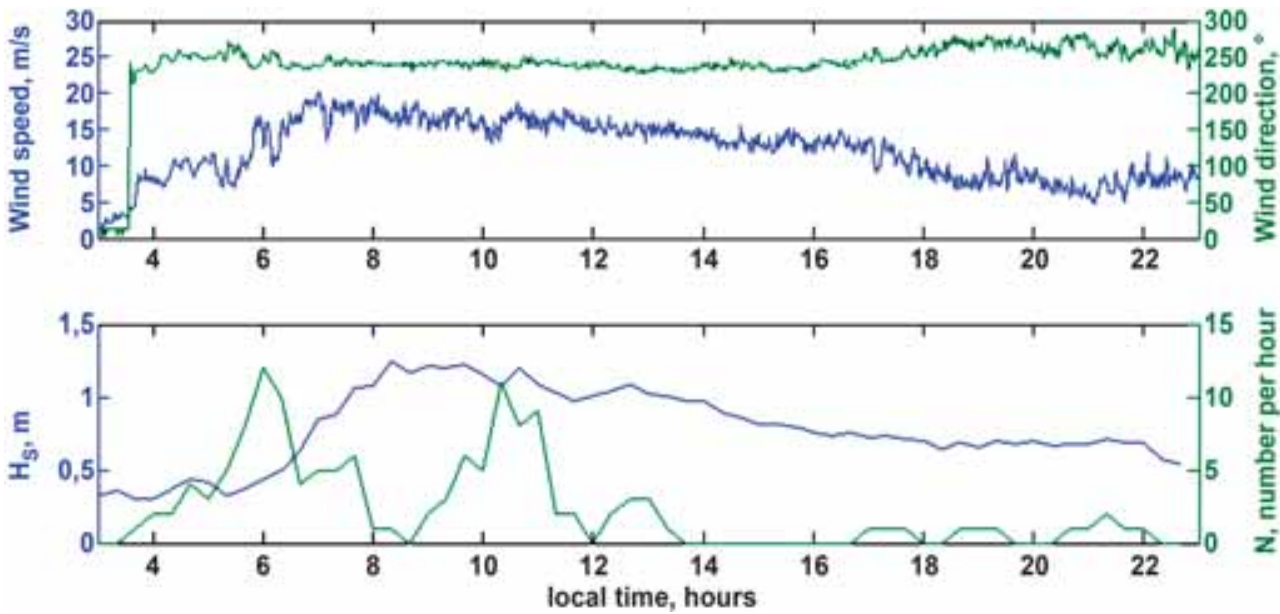

Fig. 3. The observations from the platform in Katsiveli on Oct. 14, 2009: wind speed and direction (top), the significant wave height $H_{s}$ and frequency of occurrence of waves of the anomalous height (bottom)

on the value of kurtosis for all recordings of the experiment. The value of kurtosis is three for the linear waves, and the kurtosis deviation from three characterizes the nonlinear processes in the wave field [Janssen, 2003]. The graph shows a clear relation between the degree of waves' abnormality and nonlinear interactions. A similar relationship was reported in [Shin and Hong, 2009] for a three-year long registration of waves in the open part of the Yellow Sea. Three blue dashed lines in Fig. 5 show the logarithmic approximation of this dependence obtained for the data for 2004, 2005, and 2006 by Shin and Hong [2009]. The same form of approximation of our data reads $A_{l}=1,82 \ln \left(K_{t}\right)-0,27$. The corresponding curve is shown in the figure in red.

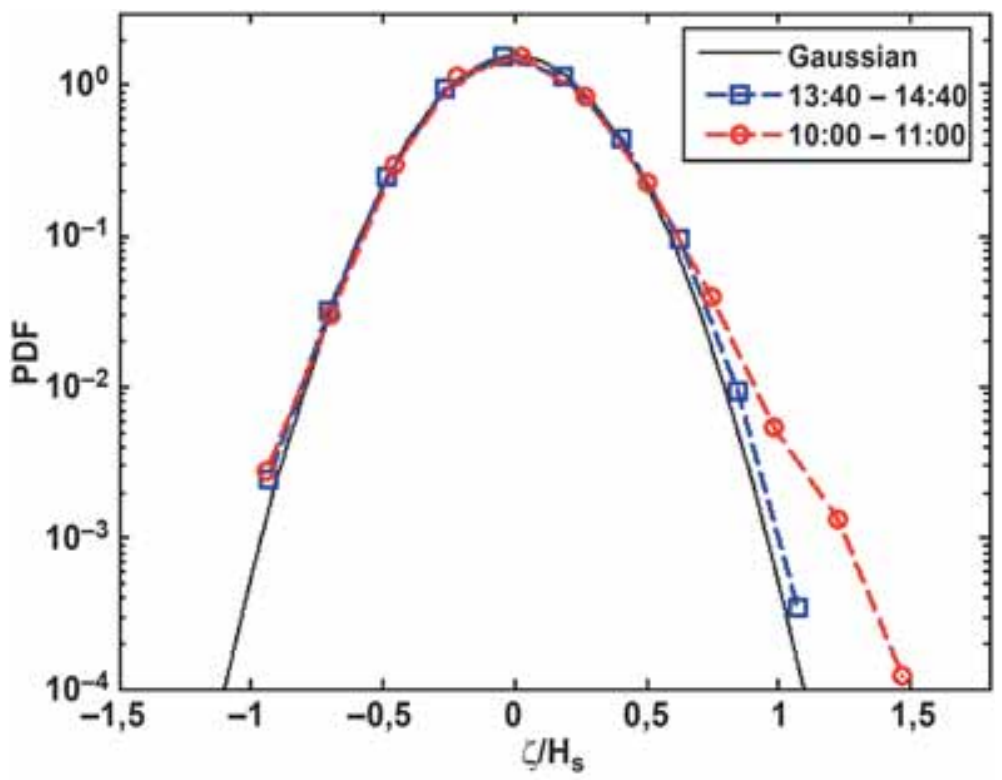

Fig. 4. PDF of the normalized sea surface elevations for the time intervals of higher and lower occurrence frequency of waves of the anomalous height. Solid line shows the normal distribution 


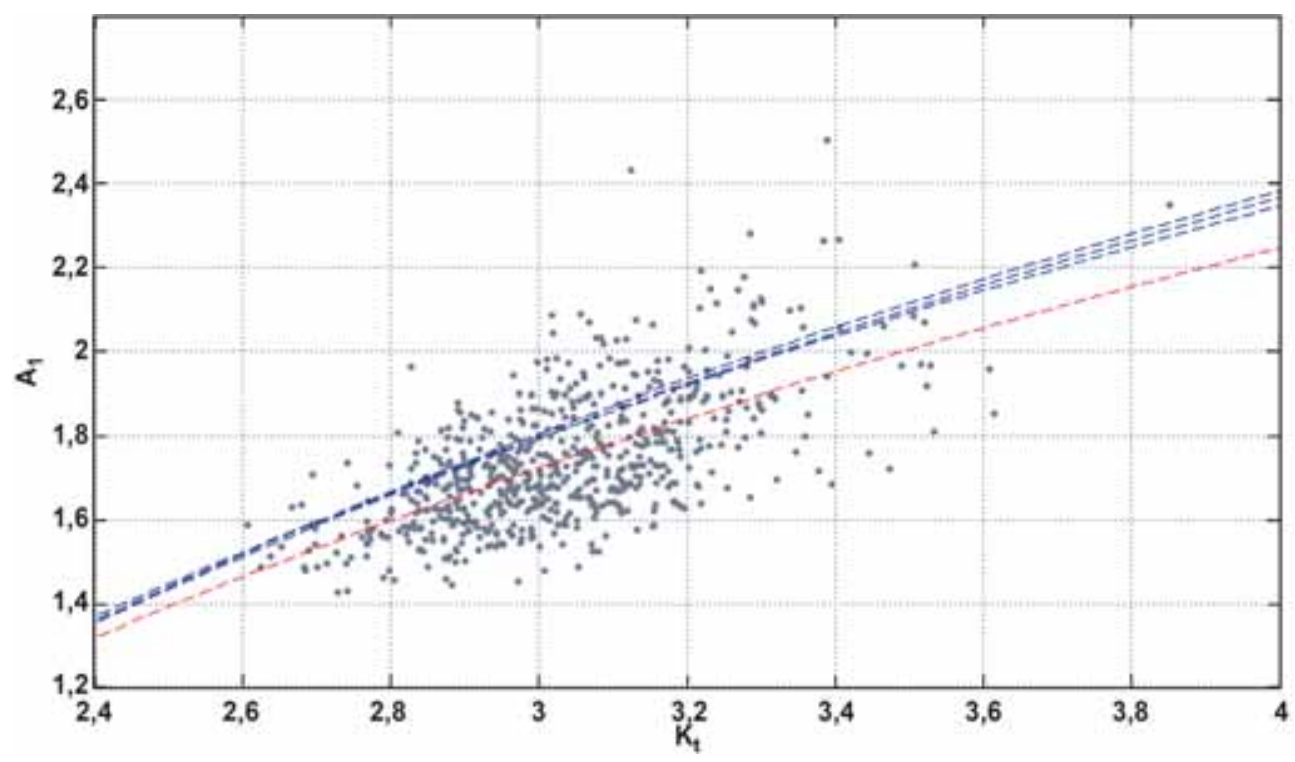

Fig. 5. The relation between the abnormality index and kurtosis. The points represent the experimental data; the red line is the average dependence; the blue lines are the results of Shin and Hong [2009]

It demonstrates the agreement between the observations in the Black Sea and the Yellow Sea. The absence of an exact correspondence between the approximating curves may be due to differences in measurement techniques [Shin and Hong, 2009]. Note also that our data allow the estimation of $B F I$ from the wave spectra, but we, like Shin and Hong [2009], were not able to identify its connection with the abnormally high waves.

Review of the experimental results shows that formation of the anomalously high waves is connected with nonlinear processes in the sea wave field. The index

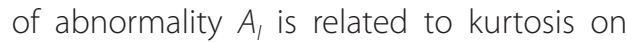
average, and this interrelationship is similar to the one obtained in the Yellow Sea. The frequency of occurrence of the abnormally high waves varies considerably over a time scale of several hours. It follows that the most favorable conditions for the formation of killer waves in the Black Sea are realized at such time scales. The search for these conditions is the natural approach to predict the most dangerous storm situations when encounters of ships with killer waves are possible.

\section{THE ANALYSIS OF WIND AND WAVE CONDITIONS OF THE OCCURRENCE OF ABNORMAL WAVES}

The definite separation of sea surface waves into the swell and the wind systems, as a rule, is associated with a certain difficulty, especially when the directions of propagation of the waves of both systems are similar. Therefore, below, we will describe, in detail, the procedure for the spectral partitioning that is applied in this paper. Fig. 6 shows an example of the wave spectrum on Oct. 14, 2009, estimated from the measurements of the "big" and "small"WGAs. The figure also shows wind speed and direction, averaged over the time-period for which the spectrum was estimated. The frequency spectra $S_{1}(f)$ were estimated by the Welch's method (averaging the spectra estimations obtained from halfoverlapping segments of realizations). The frequency-angular spectra $S_{2}(f, \phi)$ were estimated by the maximum-likelihood method [Johnson, 1999]. The vertical axes represent the direction of the waves, i.e., the geographical azimuth from which the waves come. This manner of presentation of the spectra is useful for comparison with wind direction, indicating "where from". Fig. 6 shows two two-dimensional spectra of the sea 

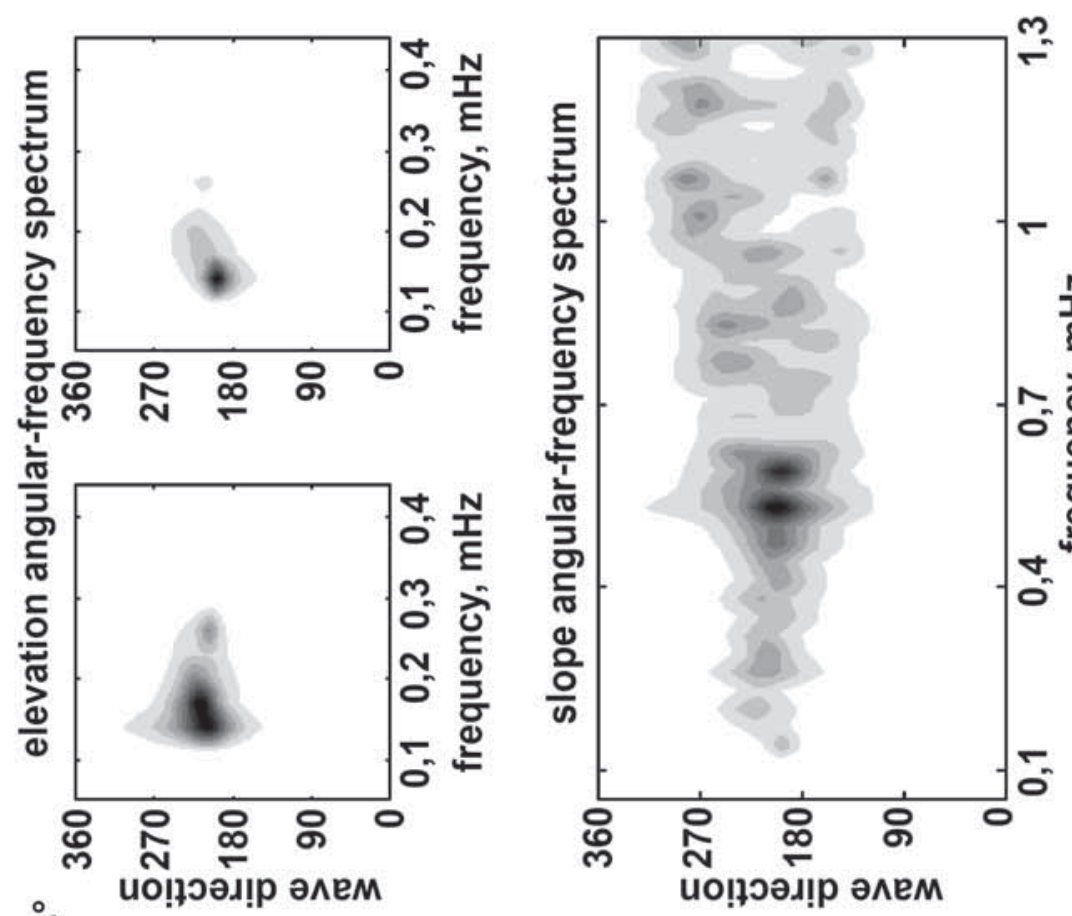

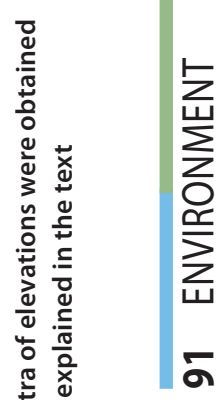
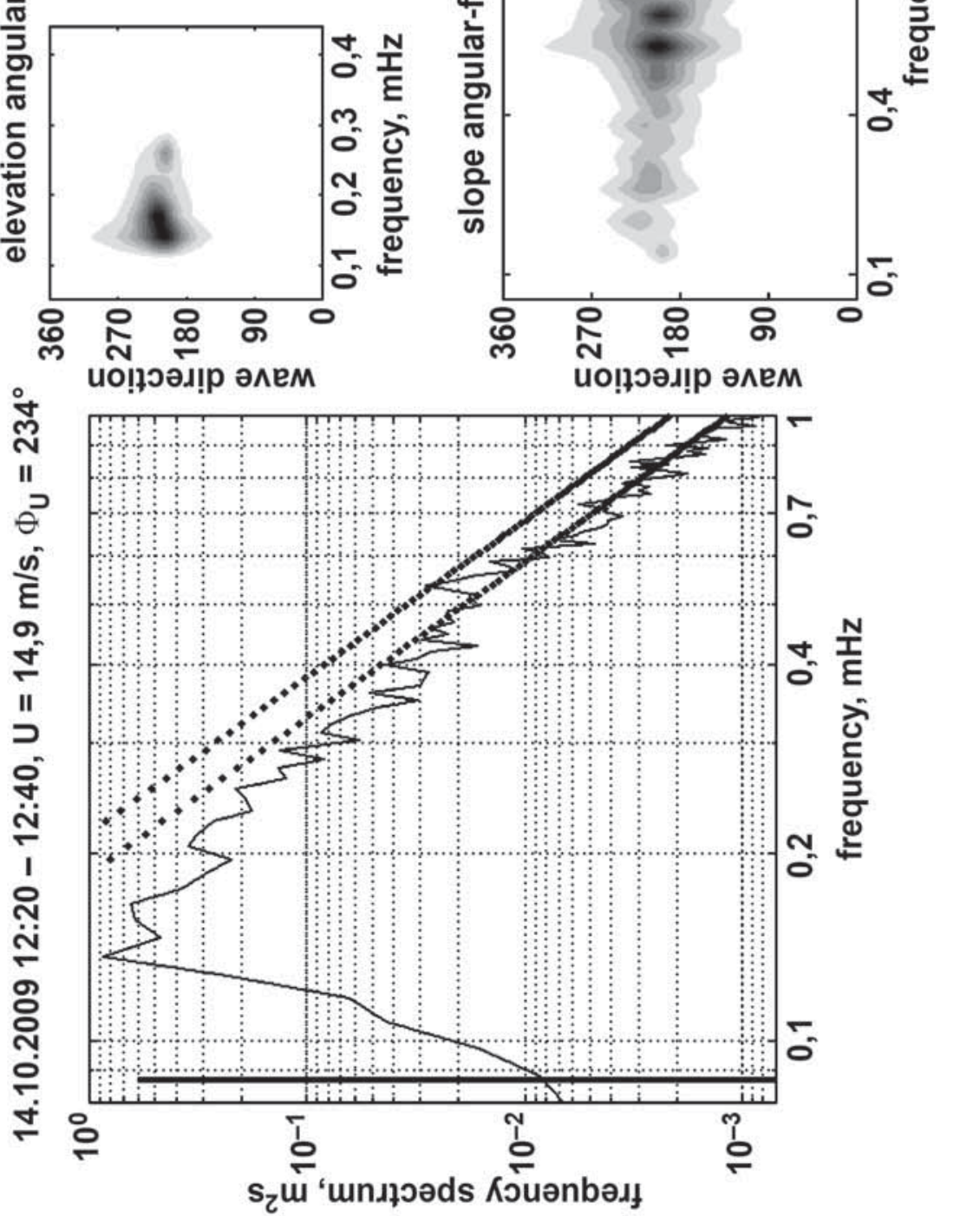

แั

ก

ํํํ 은

خ

ฮั 
surface elevations obtained from the data of the "big" and "small" WGAs. Both spectra give the same overall pattern, but the data of the "big"WGA reveal details of the angular distribution of energy for the waves with the greatest lengths (in Fig. 6, $0.1-0.2 \mathrm{~Hz}$ frequencies correspond to the wavelengths of up to $70 \mathrm{~m}$ ).

Since the wave spectra subside rapidly with increasing frequency, only the region of the spectral peak is clearly visible in a linear scale. To get an idea of the spectrum of higher frequencies, which is usually associated with local wind, it is convenient to consider a two-dimensional slope spectrum, which is, in the angular-frequency representation, proportional to the value of $f^{4} S_{2}(f, \phi)$. Specifically this quantity estimated from the data of the "small" WGA is shown in Fig. 6 as the spectrum of the slopes. As Fig. 6 shows, propagation direction of the short-wave part of the spectrum corresponds to the direction of wind.

It should be noted that traditional methods for evaluating a two-dimensional wave spectrum from measurements by the WGA (the maximum likelihood estimation and the maximum entropy estimation) overestimate the angular width of the spectrum [Young, 1994]. Therefore, our data do not allow using the angular width of the spectrum to separate swell and wind waves. In the plot of the frequency spectrum (Fig. 6, left sub-plot), the vertical line marks the Pierson-Moskowitz spectral peak frequency calculated using the local wind speed $U: f_{P M}=0,83 g /(2 \pi U)$ [Komen, et al., 1994]. If we consider the Piearson-Moskowitz spectrum as fully developed, then the waves of the spectral peak can be attributed to the swell when the spectral peak has a frequency of less than $f_{P M}$. In our case, this method of separation of swell and wind waves is not suitable. A more effective approach proposed by Hanson and Phillips [1999] is based on the theory of the equilibrium range of Phillips [1985]. To explain it, the plot of the frequency spectrum shows the Toba spectra as two dotted lines $S(\omega)=a g u_{*} \omega^{-4}$, where $\omega=2 \pi f$, $u_{*}$ is the friction velocity in the air, while the coefficient $\alpha$ for the two lines is equal to 0.06 and 0.11. According to Hanson and Phillips [1999], the frequency spectrum of the wind system associated with local wind in the area to the right of its spectral peak must lie in the band formed by these lines. This is exactly what we see in Fig. 6 . The spectral peak of the wind system defined in the frequency spectrum by means of this criterion is clearly seen on the frequency-angular spectrum of the slopes and the direction of the waves of this peak area corresponds to the direction of local wind. We emphasize that, in this case, separation is possible, despite the fact that the spectrum, at first glance, looks like having a single peak and the directions of the wind system and of the swell waves are similar.

Having relatively long-time records of sea waves, one can confirm the verity of the separation considering the history of the wave spectrum. Often, in such situations, swell waves are clearly distinguished by comparing their peak with the Pierson-Moskowitz spectral peak frequency. Then, with increasing wind speed, the frequency peak of swell waves remains practically invariable, while the peak of developing wind systems, isolated in the frequency-angular spectrum using the Hanson and Phillips method, evolves in the direction of decreasing frequency. Note, that for the application of this approach, it is sufficient to know the Toba spectrum level only approximately. Therefore, in our analysis, the value of the friction velocity was estimated by the aerodynamic bulk formula $u_{*}=$ $=\sqrt{C_{D}} U$, where drag coefficient was set to $C_{D}=1.5 \cdot 10^{-3}$.

Fig. 7 illustrates the analysis of the wind and wave conditions for Oct. 14 based on the approach described above, when the frequency spectrum and the frequencyangular spectra of elevations and slopes of the waves were considered together. In the time interval 00:00-02:00, light swell waves, arriving from the east, were observed $\left(f_{p}=\right.$ $\left.=0.22-0.25 \mathrm{~Hz}, H_{s}<0.5 \mathrm{~m}\right)$. A moderate east wind $(U=7-9 \mathrm{~m} / \mathrm{s})$ was accompanied by 

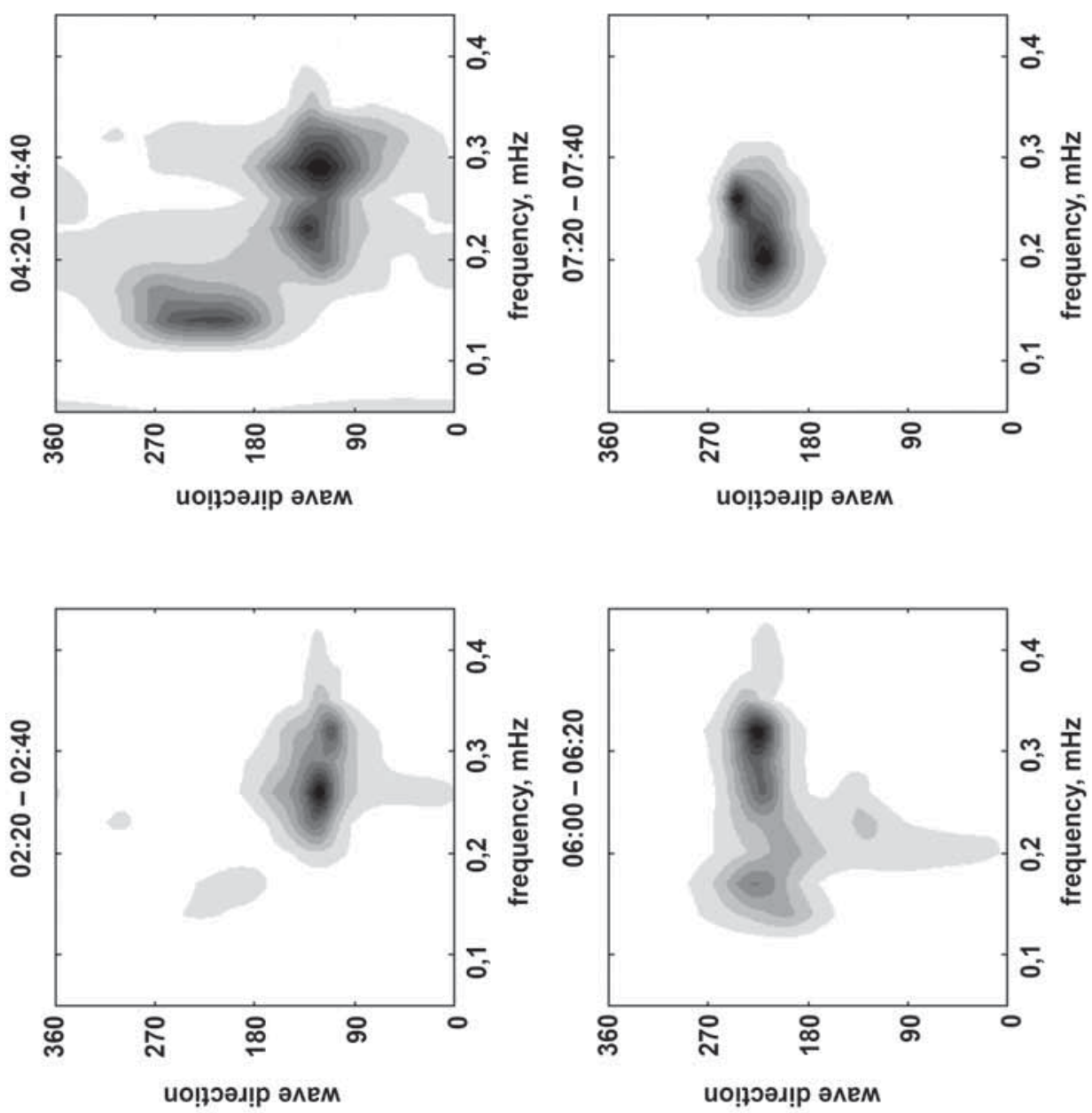

¿े
¿
$\dot{+}$
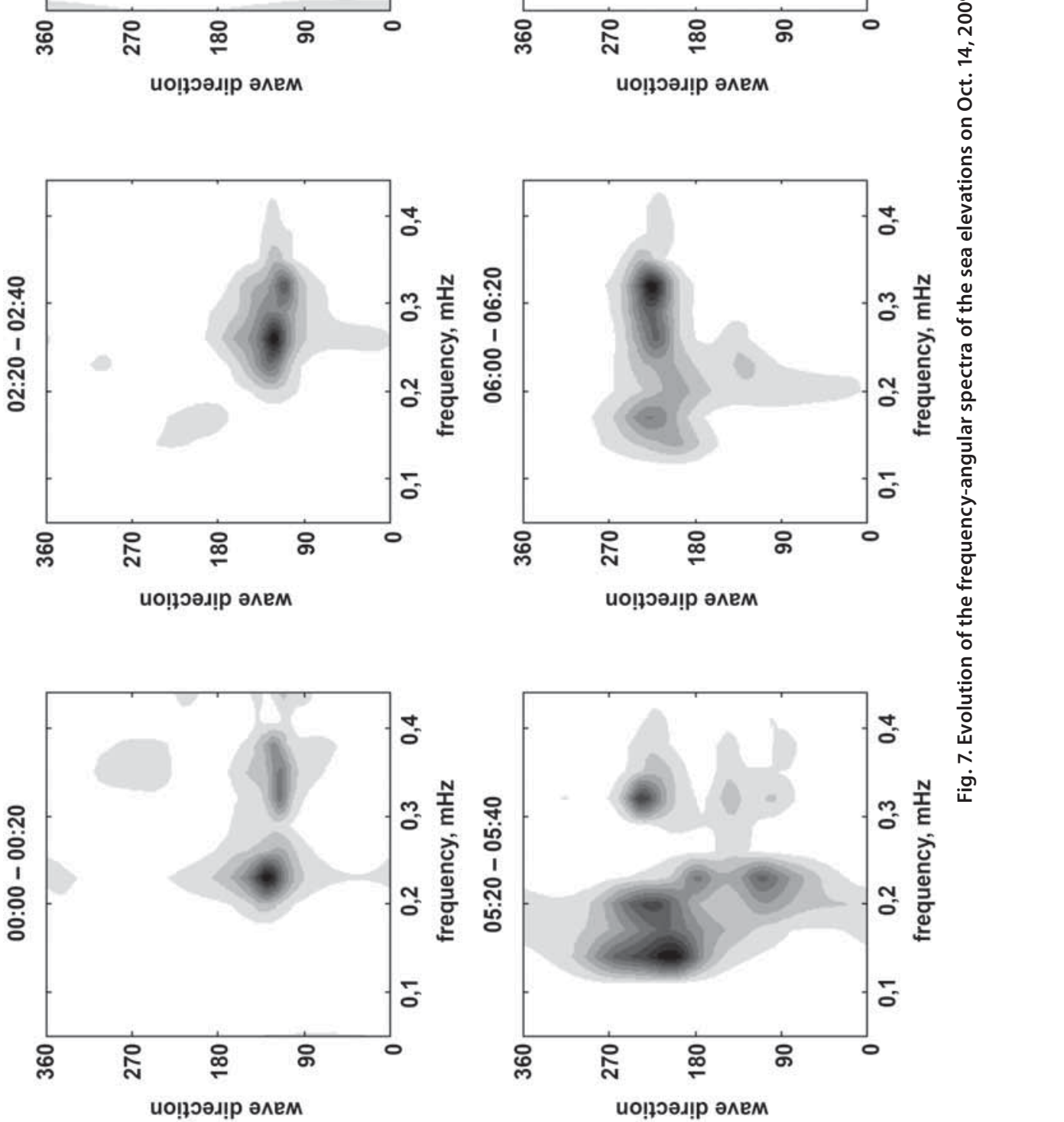
the wind-wave system $\left(f_{p}=0.33-0.35 \mathrm{~Hz}\right)$. At 2:20, a weak swell system arriving from the southwest appeared on the wave spectrum. Frequency of this system's peak was $0.14 \mathrm{~Hz}$; it did not change the significant wave height $H_{\text {s. }}$ At the same time, wind speed began to decay and wind direction to rotate. From 2:20 to 04:00, wind speed was weak $(U<3$ $\mathrm{m} / \mathrm{s}$ ) and wind direction changed from east to north and further west. The wave heights remained low $\left(H_{\mathrm{s}}<0.5 \mathrm{~m}\right)$ and the same wave systems dominated. There was also a new weak southwestern wave system with a persistent frequency peak.

At about 4:00, wind speed increased to 7$9 \mathrm{~m} / \mathrm{s}$ and its direction was set at the azimuths of $230^{\circ}-250^{\circ}$. Between 04:0005:00, there was strengthening of the southwestern swell waves and weakening of the eastern swell waves. Around 5:00, the spectral levels of these systems were already similar. During this period, the southeastern wind system with a peak frequency of $0.33 \mathrm{~Hz}$ emerged.

By 6:00, wind speed continued to increase and there was an increase of the wave heights due to increased spectral levels, both of the southwestern swell waves and of the wind system. On the frequencyangular spectra of the wave elevations, the eastern wave systems became indistinguishable. Wind speed continued to increase and the wind system continued to develop - its spectrum level increased and the peak frequency decreased. The spectral level of the swell-wave peak increased also, and its frequency decreased - there was a convergence of the peaks of the swell waves and the wind waves. By 8:00, it was already not possible to isolate the swell system from the wind system in the spectrum of the merged wave systems with a peak at $0.2 \mathrm{~Hz}$ frequency. This situation continued until 09:00. Note, that at 05:0008:00, when there was development of the wind systems on the background of already existing swell waves of the same direction, there was intensification of occurrences of the abnormally high waves (see Fig. 3).
After 9:00, a new peak of the wind system, corresponding to $0.5-0.6 \mathrm{~Hz}$ frequencies, became visible in the spectra. The new wind system was isolated based on the Hanson and Phillips technique: its spectral level fell into the band of the "Toba spectra», while the spectral level of the "old" wave system was lower. This situation was shown on Fig. 6 above, where seas consisted of the energy-carrying long-wave ("old") system and of developing wind system. Although the energy-carrying system cannot be attributed to swell waves formally, in this case, physical situation was the same as at 05:00-08:00, when there was development of the wind system on the background of already existing swell waves of the same direction. Again, there was more frequent occurrence of the abnormally high waves. From 10:00, there was a gradual decrease in frequency of the spectral peak of swell waves and a fall of its spectral level that apparently led to the disappearance of the abnormally high waves by 14:00.

The waves of abnormal heights observed in this case had periods of $6 \mathrm{~s}$ or longer corresponding to swell waves (see Fig. 3), i.e., the conditions for realization of modulational instability appear to have been satisfied. Therefore, let us consider whether we can interpret this case as realization of modulational instability.

According to theoretical concepts [Janssen, 2003; Kharif, et al., 2009; Kartashova and Shugan, 2011], modulational instability represents a discrete energy cascade, in which the wave spectrum have additional peaks corresponding to resonance conditions. An important feature of the manifestation of modulational instability is discrete changes in the spectrum as it evolves. This phenomenon can be seen in a long lab tank, where sequential stages of the cascade occur at various distances from the wavemaker [Kuznetsov and Saprykina, 2009]. Aswas demonstrated in the laboratory studies under conditions of modulational instability, a shift of frequency of the spectral peak into the low-frequency region is discrete, 
both in frequency and in the distance from the wavemaker (see Fig. 6 in [Kuznetsov and Saprykina, 2009]). At the same time, as instability develops, regular groups of waves are transformed into rather irregular wave pattern with clear-distinguished "freaks" of the form of abnormally high waves. The higher the initial steepness of the waves, the faster (the closer to the wavemaker) the new killer waves appear, but evolution of the spectrum for different initial wave steepness proceeds under approximately the same scenario.

Fig. 8 shows evolution of the frequency spectrum of the waves observed in the experiment in Katsiveli on Oct. 14, from 07:00 to 14:00. The spectra are presented in three dimensions as a function of frequency and time. Each spectrum was estimated for a one hour interval that corresponds to 38 degrees of freedom. One can see edges on the surface $S(f, t)$. The height of the high-frequency edges decreases with time while the height of the low-frequency edges grows. As a result, spectral peak downshifting takes place. At the same time, the edges are parallel to the axis of time, indicating the discrete pattern of energy transfer into the low-frequency region. It was during this time-period that killer waves were observed, as discussed above. Note that the wave recording shown in Fig.
2 refers to the time-period under discussion. The pattern of irregularity of the waves on this figure is similar to that observed in laboratory experiments when modulational instability occurred (see Fig.6 in [Kuznetsov and Saprykina, 2009]). Thus, it is reasonable to treat the situation recorded on Oct. 14 as modulational instability, which was accompanied by the formation of waves with abnormal heights.

Let us discuss the issue of strengthening of swell waves by local wind. The area of the storm is a source of swell waves propagating in the direction of wind in the storm area. Further, due to the angular and dispersion divergence of the waves, the swell wave spectrum becomes narrow, both in frequency and direction. It is exactly this feature of swell waves that could result in modulational instability [Onorato, et al., 2009] in the area remote from the zone of the storm. However, due to divergence and attenuation of the waves, their steepness decreases and, therefore, intensity of nonlinear processes decreases also. In order to instability to occur, the strengthening of swell waves is necessary. It can be assumed that strengthening of swell waves on Oct. 14 was due to the wind that blew in the direction of swell waves. Note that different versions of the traditional wave models WAM correctly describe evolution of waves only for long (an

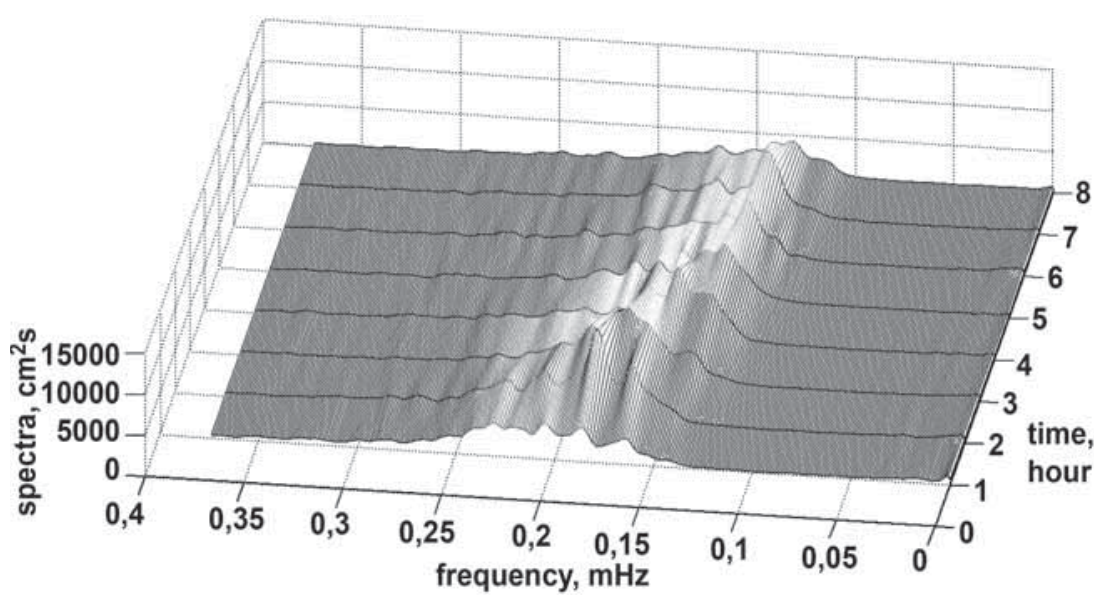

Fig. 8. Evolution of the wave spectrum from 07:00 to 14:00 on Oct. 14, 2009. Label 1 on the time axis corresponds to 07:00 
hour or more) time-periods. This is due to the fact that they treat four-wave interactions just as resonant [Komen, et al., 1994]. At the same time, "quasi-resonant" four-wave interactions lead to a much more rapid evolution of the spectra [Annenkov and Shrira, 2009; Badulin, et al., 2009]. In [Badulin, et al., 2009] the mechanism of amplification of swell waves due to "fast" quasi-resonant four-wave interaction with wind waves propagating in the same direction has been simulated. As the result of this interaction, there was a rapid transfer of energy from the wind waves to the swell, while the development of wind waves practically ceased. It is possible that precisely this situation was observed on Oct. 14, 2009.

The procedure of separation of swell and wind waves described above was applied to all processed records. Wind-wave situations were divided into three classes: "1" - the main spectral peak corresponds to the system of wind waves, " 2 " - the main spectral peak is due to the system of swell waves and swell direction corresponds to wind direction within 45 degrees; " 3 " - mixed seas with prevailing swell waves, including calm conditions when the system of wind waves was absent.

Only four (10\%) of the 40 recorded abnormally high waves were observed in the situation with purely wind seas; the rest of the abnormally high waves appeared in the swell system. Of these, 28 (70\%) were observed in situation " 2 " when the direction of propagation of swell waves was close to that of wind.

Thus, on Oct. 14, 2009, there was amplification of swell waves by wind of the same direction. This resulted in a narrow spectrum of relatively steep swell and high frequency of occurrence of the abnormally high waves. These waves presumably formed as the result of modulational instability. This scenario of higher occurrence frequency of killer waves (high-risk situations) dominated through the entire experiment.

\section{THE SIMULATION OF WIND-WAVE CONDITIONS OF THE KILLER WAVES FORMATION}

Let us consider what the synoptic conditions are conducive to the local wind-wave situations of higher occurrence frequency of the abnormally high waves. For this, we will perform a model reconstruction of the storms on Oct. 14, 2009 (discussed above) and on Feb. 1, 2003, when there were abnormal waves in the area of Gelendzhik (as described in [Divinsky, et al., 2004; Kuznetsov, et al., 2006; Kuznetsov and Saprykina, 2009]). That is we will analyze the wind-wave fields in the Black Sea for the periods corresponding to these instrumental observations.

For the reconstruction of the wave field, the wind fields at the $6-\mathrm{km}$ grid with a timestep of one hour were calculated with the help of the regional mesoscale atmospheric model MM5 [Dudhia, 1993], developed by the US National Center for Environmental Prediction/National Centers of Atmospheric Research (NCEP/NCAR). To set the boundary conditions, reanalysis data NCEP/NCAR, presented in the public domain, were used. The wave spectra were calculated using the wind fields and the model WAM-C4 [The WAMDI group, 1998; Yefimov, et al., 1998].

At night on Oct. 13, preceding the formation of the abnormally high waves at the platform in Katsiveli, an atmospheric cold front passed across the Black Sea. Fig. 9 illustrates the wind speed field at 21:00 and 24:00, local time, on Oct. 13. The wind speed in the front area exceeded $16 \mathrm{~m} / \mathrm{s}$ and wind was primarily of the northern direction. Accordingly, the zone of the storm was moving with the zone of the strongest wind. Fig. 10 shows the fields of wind speed and waves at 3:00, local time, on Oct. 14. It can be concluded from the figure that in the neighborhood of a point with the coordinates $43^{\circ} \mathrm{N} 33^{\circ} \mathrm{E}$, there had already been waves with the period of about $6 \mathrm{~s}$. Their group velocity was about $5 \mathrm{~m} / \mathrm{s}$. Therefore, propagating in the direction of Katsiveli, they were able to reach the platform after 6 hours in the form of 


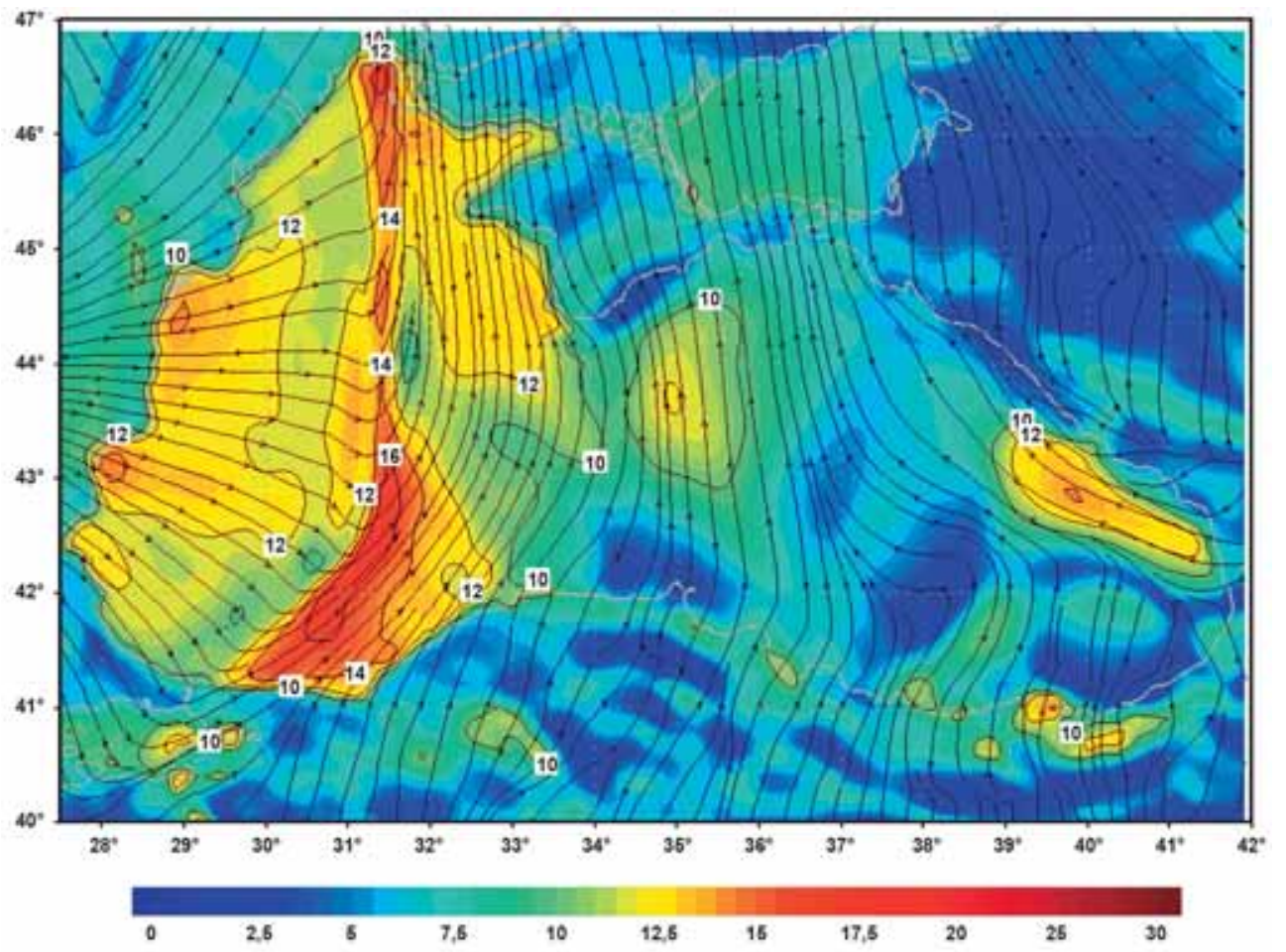

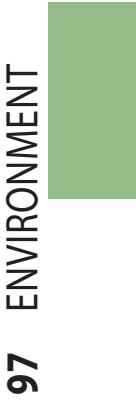

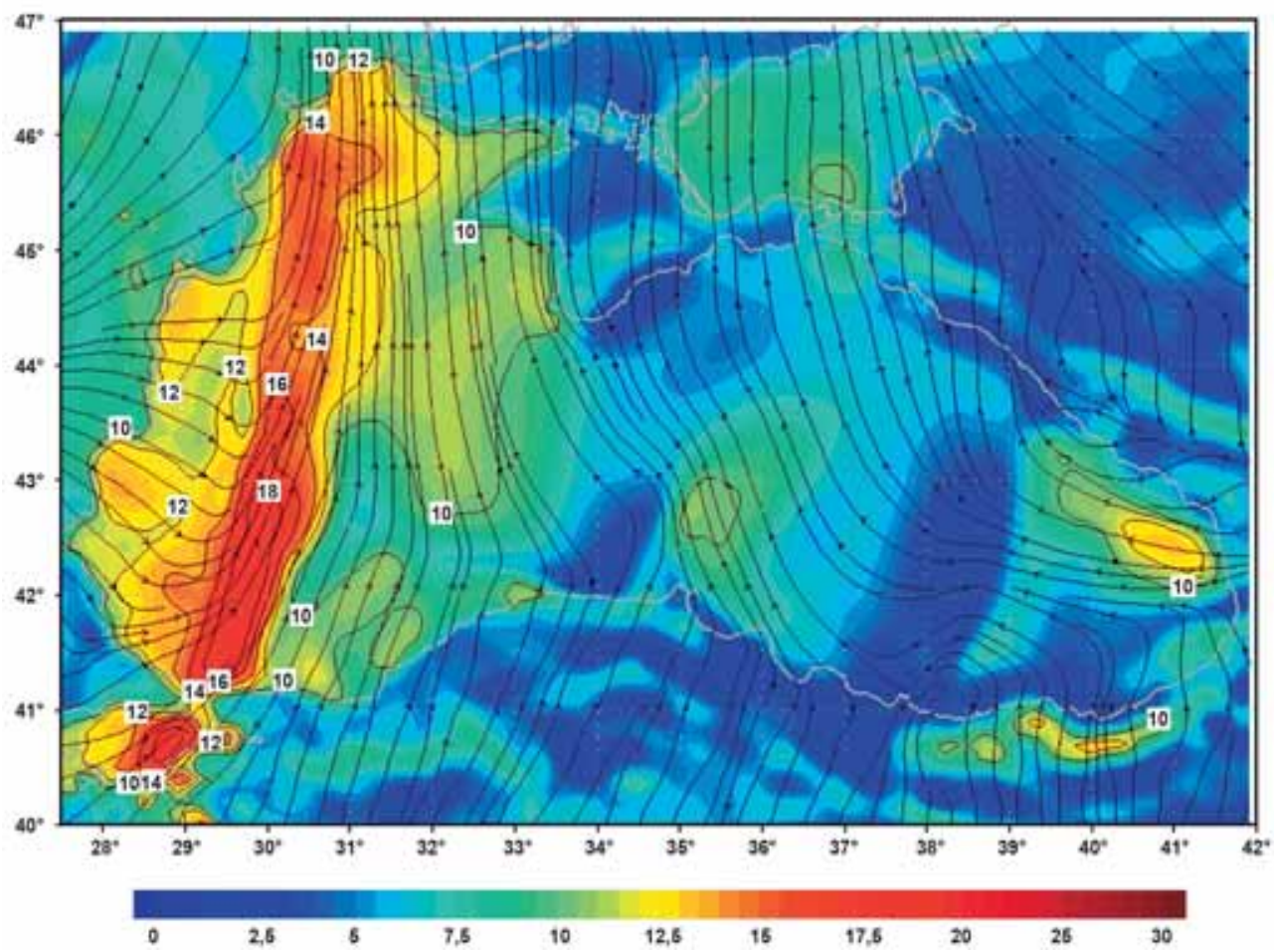

Fig. 9. The results of the simulation. Movement of the atmospheric front over the Black Sea. The fields of wind speed and direction at 21:00 (top) and 24:00 (bottom) on Oct. 13, 2009, local time. The color scale gives wind speed in $\mathrm{m} / \mathrm{s}$ 

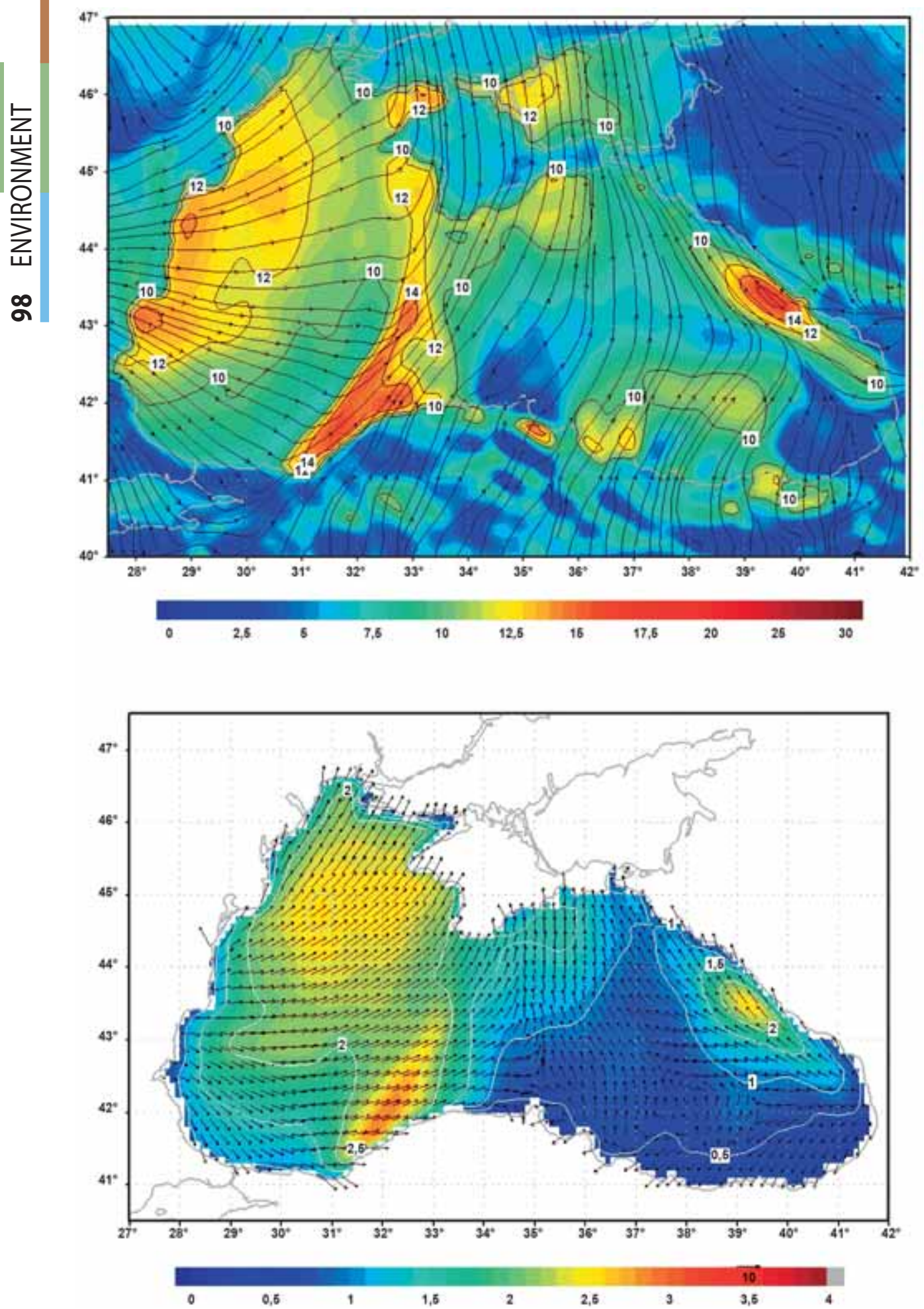

Fig. 10. The results of the simulation. The field of wind (top) and waves (bottom) on Oct. 14, at 3:00, local time. The color scales represent wind speed in $\mathrm{m} / \mathrm{s}$ and wave height in $m$; the arrows indicate the direction of the waves; the length of the arrows shows the wave period in $s$ when compared to the scale of $10 \mathrm{~s}$ given in the area of the color scale 


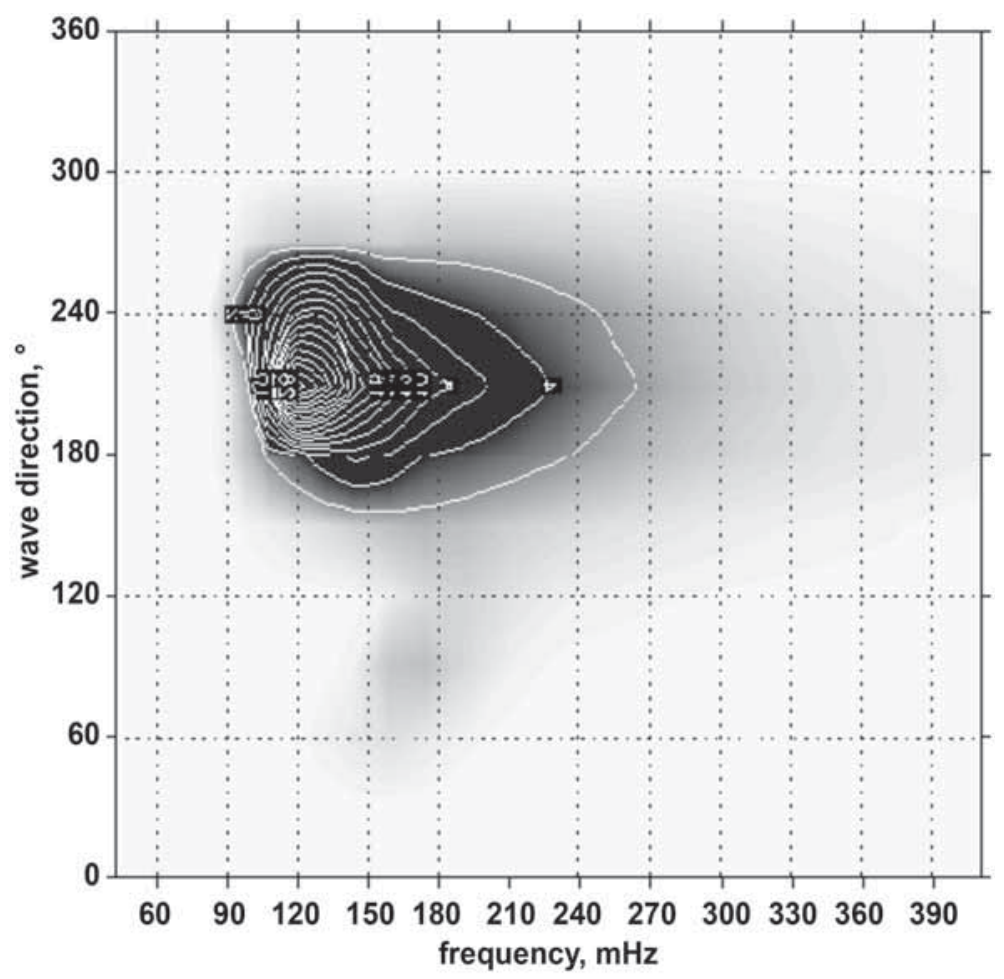

Fig. 11. The simulated spectrum of the waves at 12:00, local time, on Oct. 14, 2009

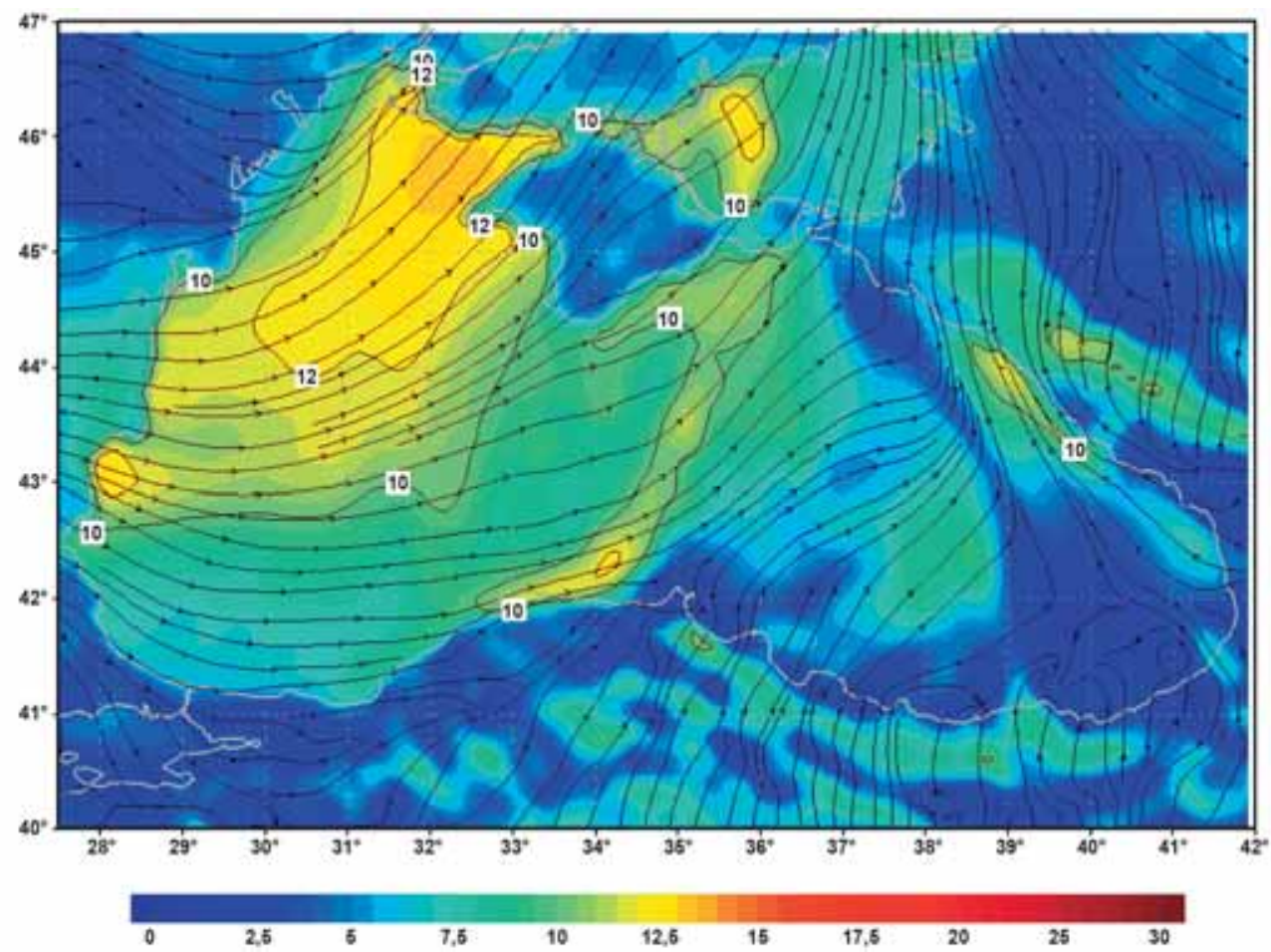

Fig. 12. The simulated wind field at 9:00, local time, on Oct. 14, 2009 

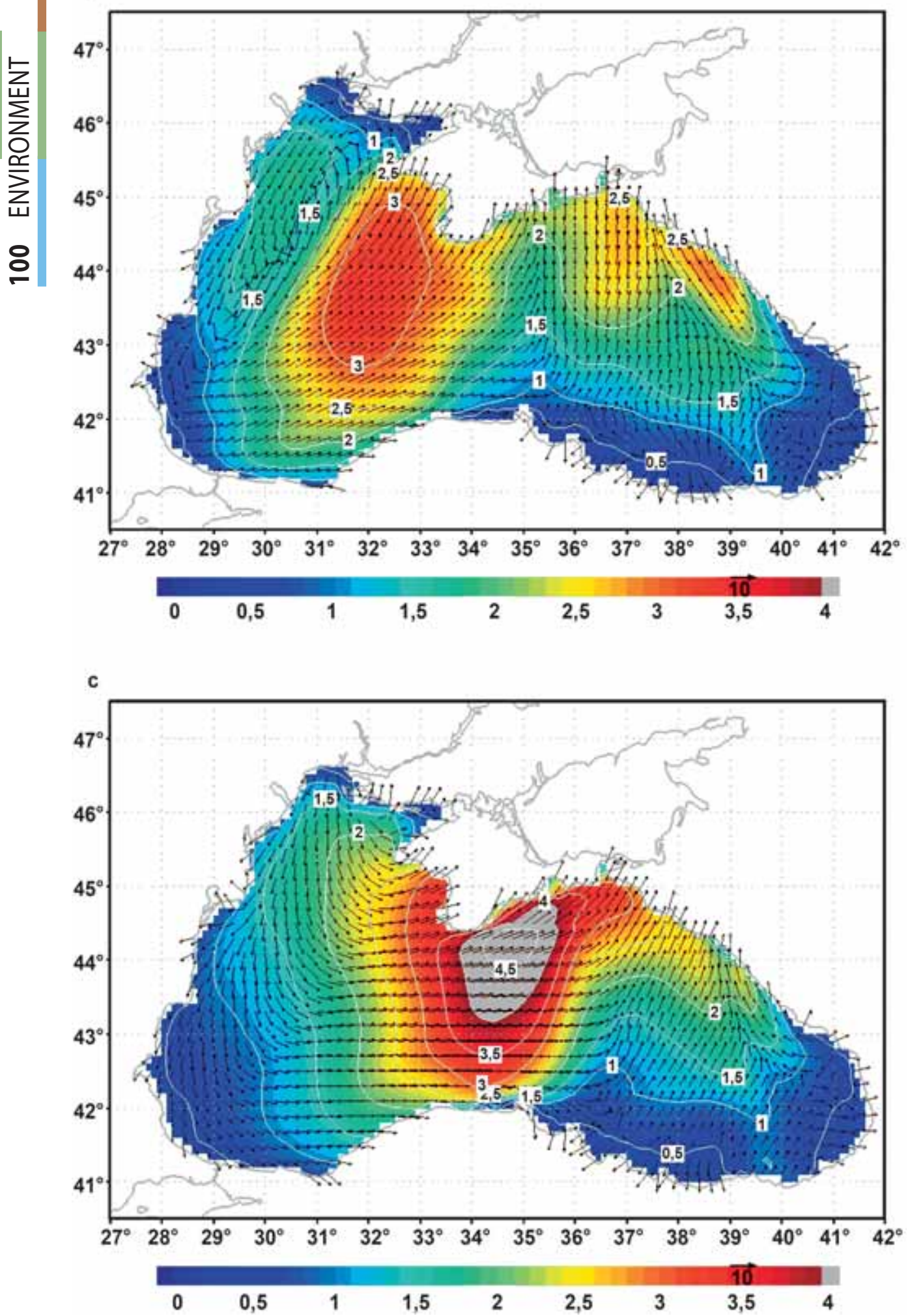

Fig. 13. The background conditions of the formation of the 12-meter killer wave in the area near Gelendzhik. $\Rightarrow$ 
b

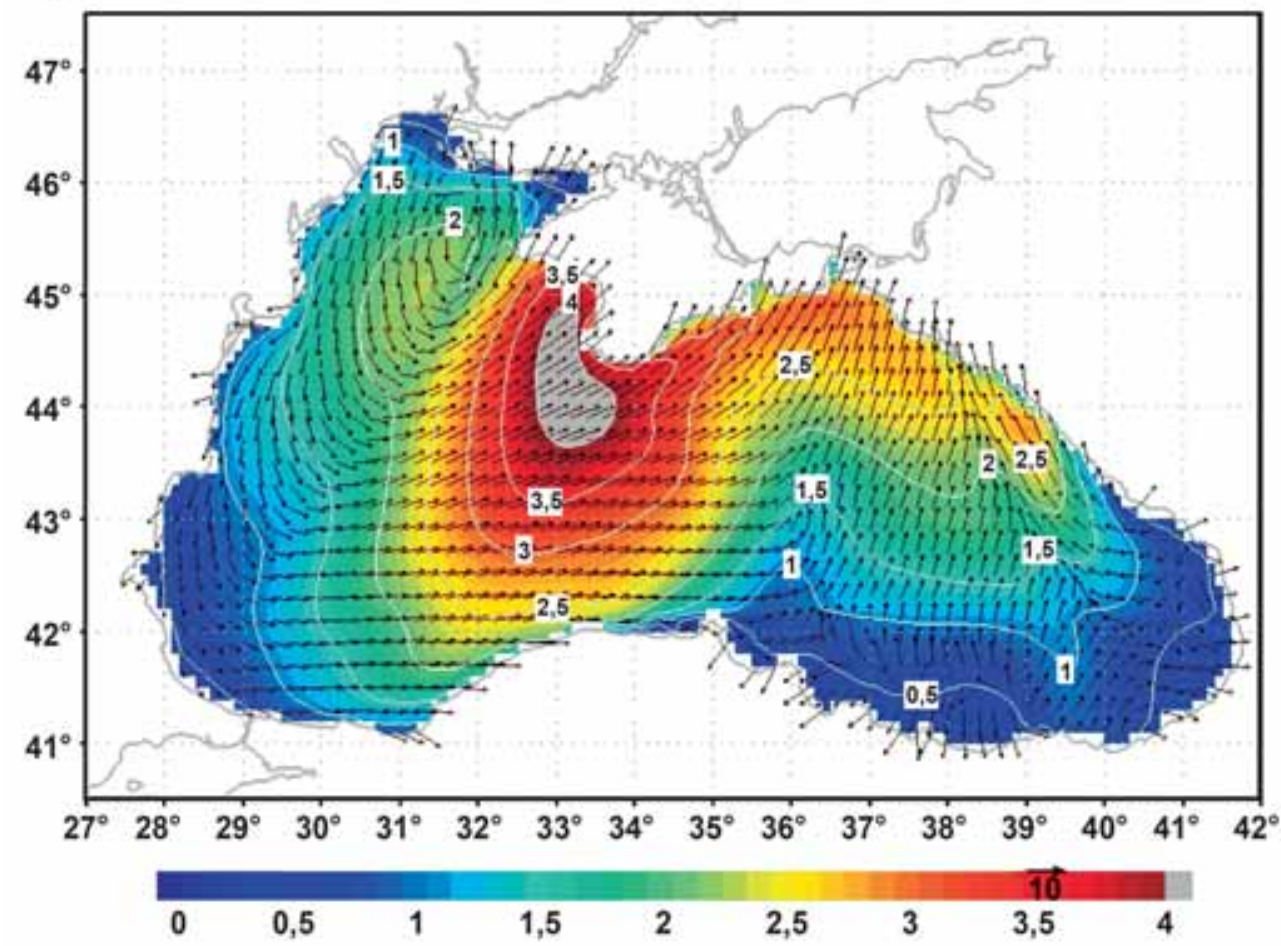

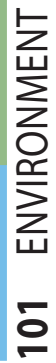

d

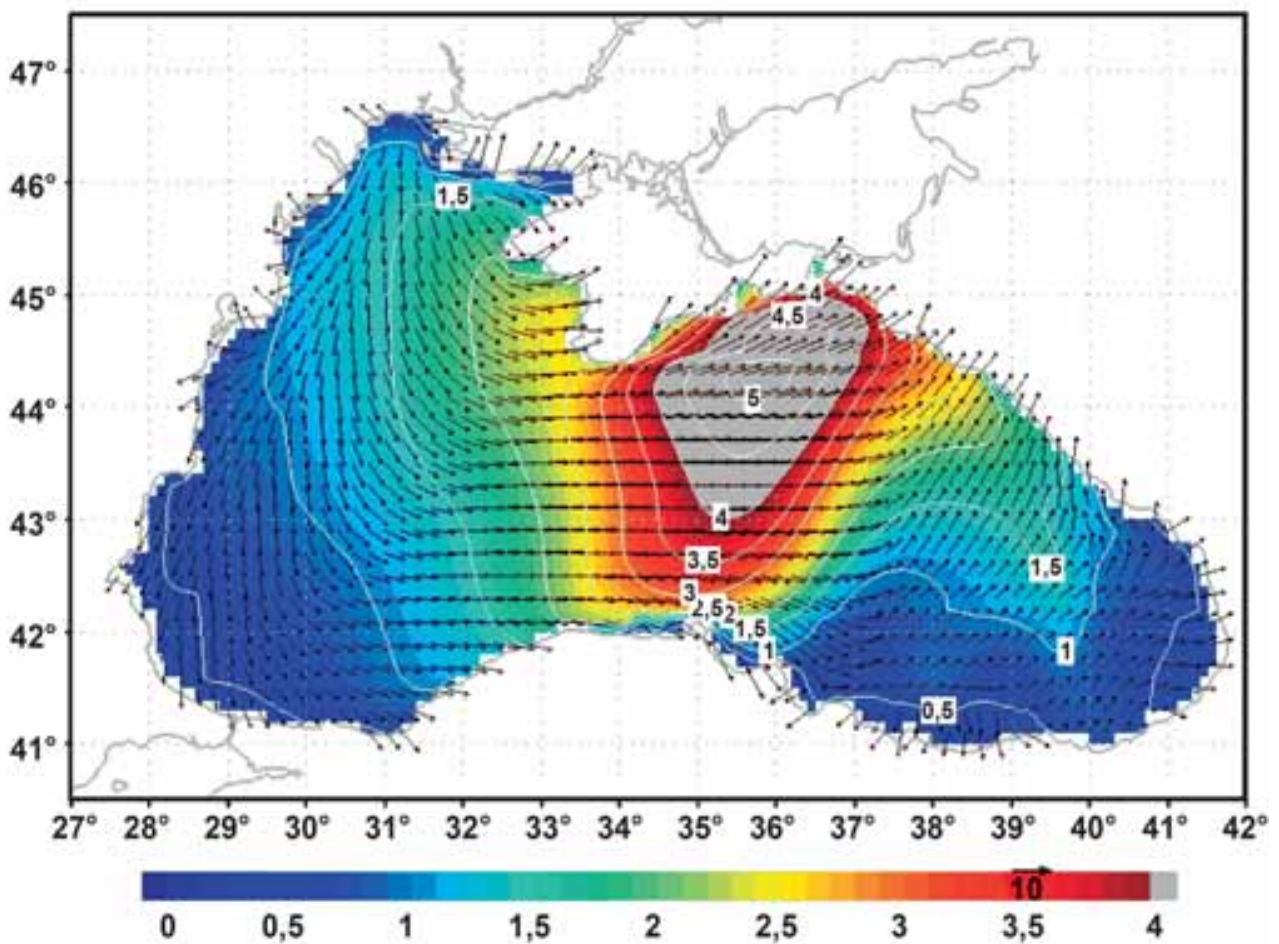

The simulated field of waves for 1:00 (a), 4:00 (b), 7:00 (c), and 10:00 (d) hours, local time, on Feb. 1, 2003. The notation is the same as in Fig. 10 


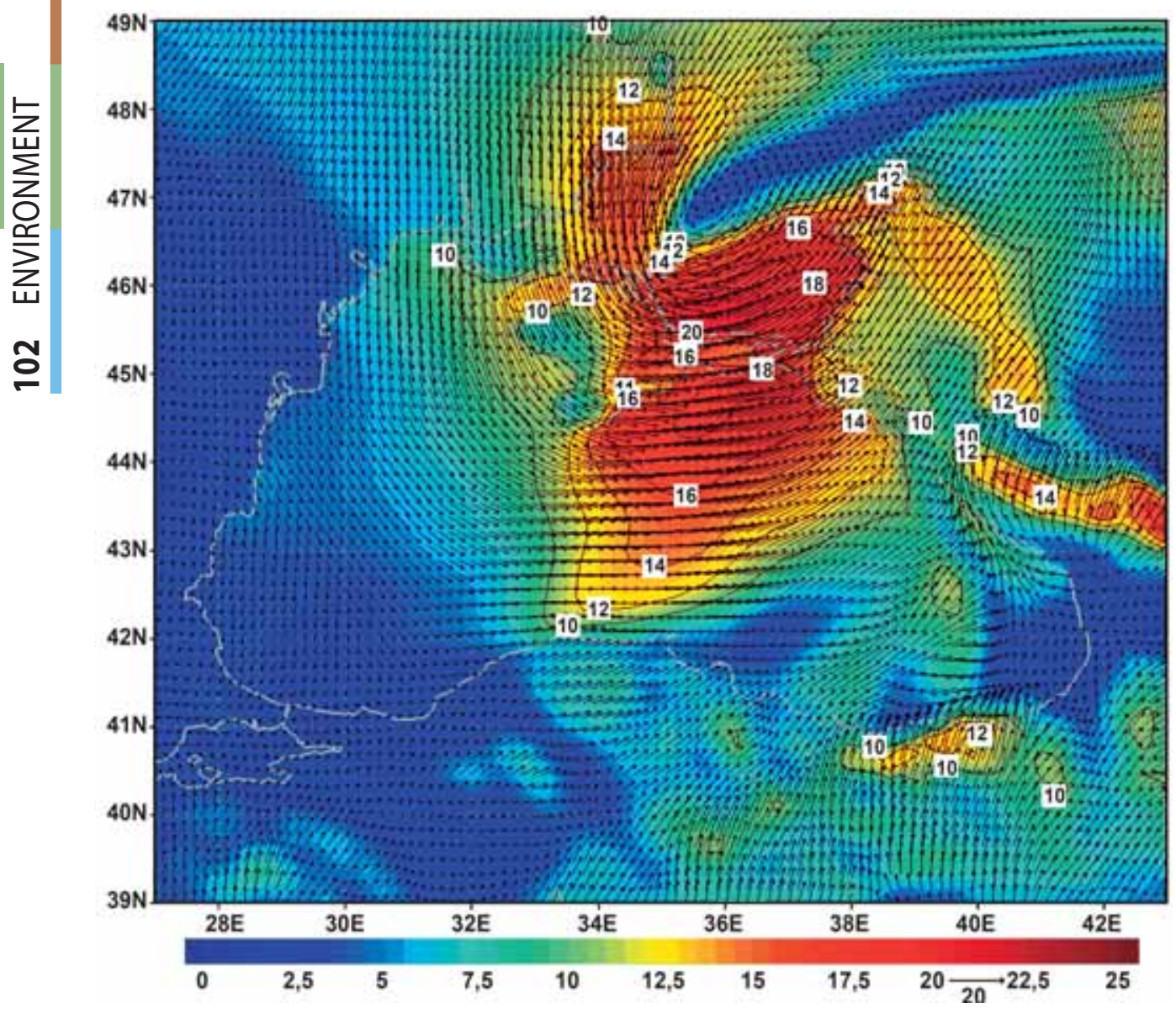

Fig. 14. The simulated wind field at 8:00 and 10:00 (opposite page), local time, on Feb. 1, 2003

swell waves with the observed, at the time, frequency and direction (see Fig. 7).

Fig. 11 shows the simulated spectrum of the waves for the region of the platform at 12:00 on Oct. 14. Comparing it with the spectrum in Fig. 7, estimated from the in situ data of the time interval 12:20-12:40, one can see the correspondence of the spectral peaks, both in direction of the waves and frequency: frequency of the peak for the simulated spectrum and the measured spectra are $0.12 \mathrm{~Hz}$ and $0.13 \mathrm{~Hz}$, respectively. Thus, in the situation discussed above, there were indeed swell waves coming from the storm area of the central part of the Black Sea.
Fig. 12 shows the wind speed field at 9:00 on Oct. 14. The simulated and observed wind directions coincide $\left(220^{\circ}-230^{\circ}\right.$, compare with Fig. 3). Thus, the model simulation of the wind and wave fields in the Black Sea allows one to conclude that the interpretation of the wind-wave situation, made based on the field measurements at the location of the platform, corresponds to the synoptic situation. There were the abnormally high swell waves when the direction of their propagation was close to that of wind.

Now, let us consider the situation on Feb. 1, 2003, when, in the area of the recording buoy of the Southern Branch of the 10, a 12-m high killer wave, discussed in [Divinsky, et al., 


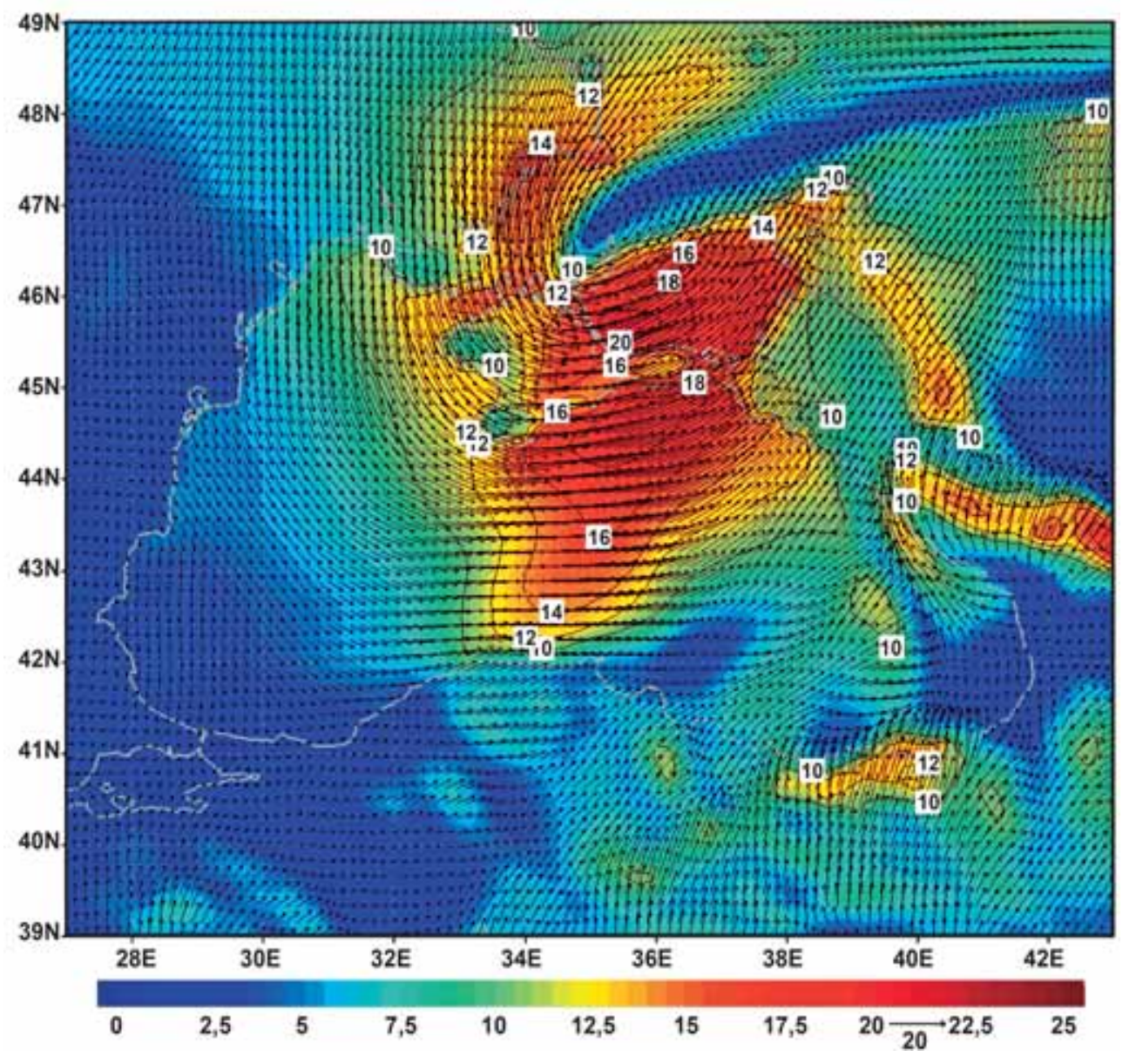

Continued Fig. 14

2004; Kuznetsov, et al., 2006; Kuznetsov and Saprykina, 2009], was observed. We should emphasize that, in contrast to the abnormally high waves on Oct. 14, 2009, examined for research purposes, the Gelendzhik killerwave represented a real danger. Details of the wave situation, obtained with the Datawell buoy, including frequency and the frequency-angular spectra of waves, are given in the papers cited. Period of this wave was 11-12 s and the group velocity of the waves of this frequency was $9-10 \mathrm{~m} / \mathrm{s}$, i.e., almost two times higher than for the swell waves on Oct. 14, 2009. Therefore, we can expect that the formation of killer waves is associated with the previous synoptic situation during the period of time of less than 10 hrs, i.e., two times shorter than in the previous case.

Analysis of the calculated wind field showed that, during this period, the western and central parts of the Black Sea were in the zone of intense local cyclone moving northeast. In these parts of the sea, there was an extensive area of a violent storm with wind speed exceeding $20 \mathrm{~m} / \mathrm{s}$ and of a primarily northeastern direction. Fig. 13 shows the calculated wave fields, demonstrating the background for the formation of a killer wave up to the time of its registration. As can be seen from the Fig. 13, the region of strong storm was, over time, approaching the location of the buoy. In this region, wave 

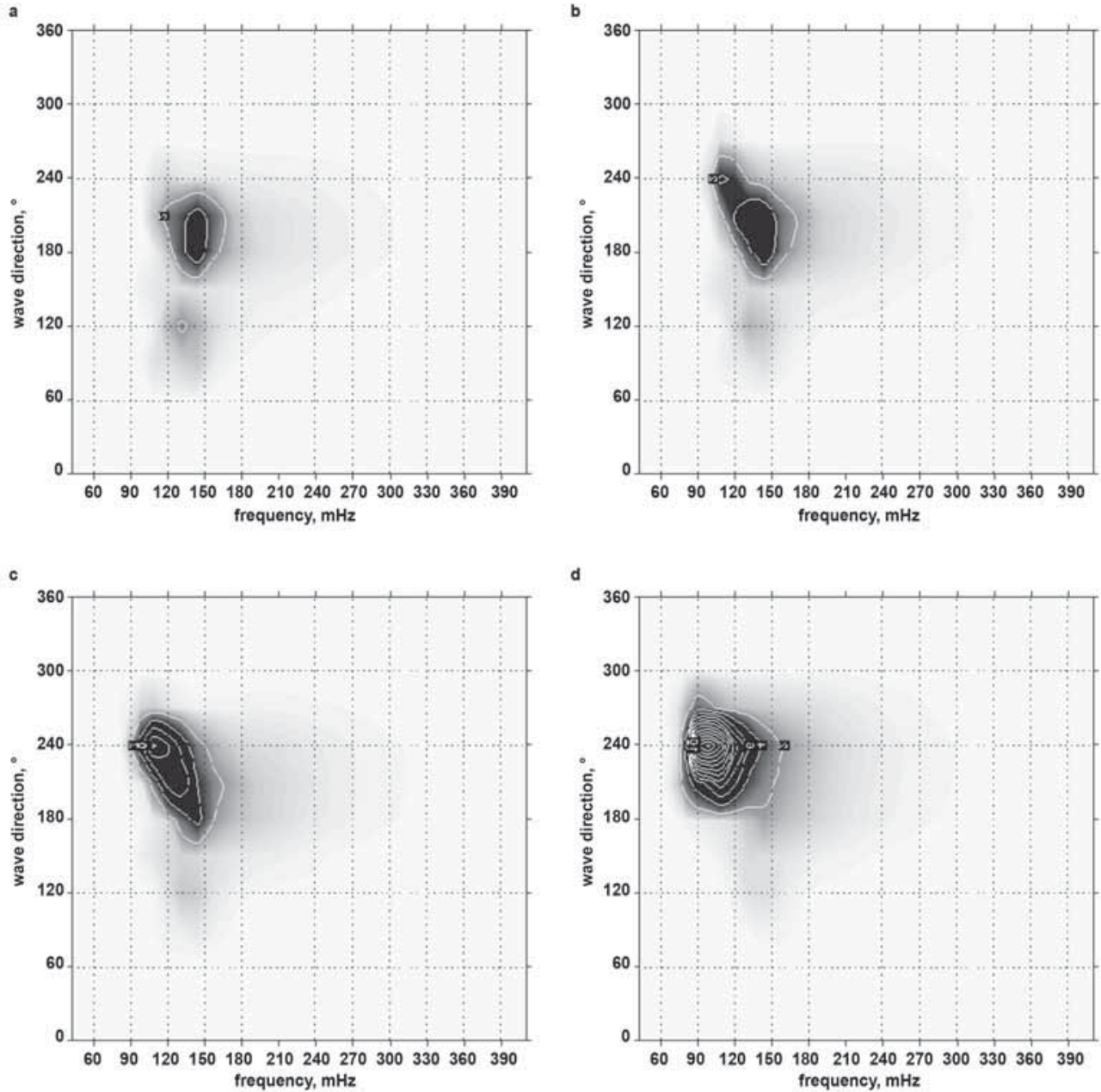

Fig. 15. The simulated spectra of the waves at 7:00 (a), 10:00 (b), 11:00 (c), and 13:00 (d), local time, on Feb. 1, 2003

height reached $5 \mathrm{~m}$, period was approaching $10 \mathrm{~s}$, and wave direction was approximately in the direction to the location of the buoy. We emphasize that, at the time of the observation of the killer wave (between 9:00 and 10:00), the storm area had not yet reached the longitude of Gelendzhik $\left(38^{\circ} \mathrm{E}\right)$. Therefore, the waves with periods longer than $11 \mathrm{~s}$ registered by the buoy should be referred to swell waves propagating in the direction of the buoy from the region of the intense storm.

The fields of wind speed at 8:00 and 10:00 hrs (Fig. 14) show that, at the point of the measurements during this time-period, wind retained its velocity at $12-14 \mathrm{~m} / \mathrm{s}$ and its direction at $220^{\circ}-240^{\circ}$ ("from"), corresponding to the direction of swell waves.

Figures 15 a-c present the calculated wave spectra for the point of the buoy location, which show the wave history prior to the observed killer wave. Fig. 15a shows that, six hours prior, there had already been the swell wave system with basic frequency of $0.15 \mathrm{~Hz}$ and the general direction of $200^{\circ}$. The waves of the swell wave system that corresponded to the killer wave (15c) had appeared three hours prior to its observation and, at this moment, their basic frequency was $0.1 \mathrm{~Hz}$, and the general direction was $240^{\circ}$ 


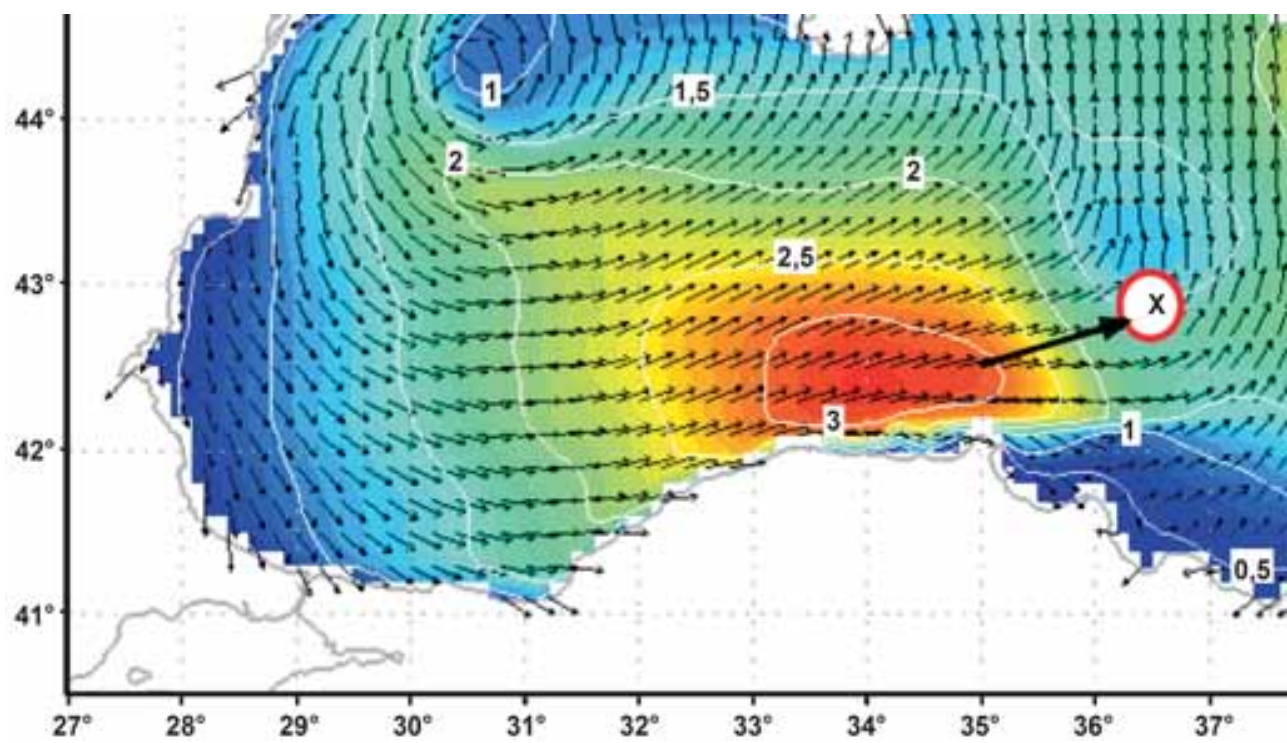

Fig. 16. Example of the implementation of the risk assessment of an encounter with a killer wave. See explanation in the text

(Fig. 15b). This interpretation corresponds to the concept of a moving source of the waves of the swell wave system (localized in the storm zone) and to the instrumental measurement of the height and frequency of the waves. The new wave system had higher wave energy (see Fig. 2a in [Kuznetsov and Saprykina, 2009]) and direction of the waves coincided with wind direction (see Fig. 14). Fig. 15d allows assessing the quality of the model reconstruction of the spectra. Comparing it with the instrumental estimation of the spectrum for the same time (see Fig. 1 in [Kuznetsov and Saprykina, 2009]), we can conclude that the model reproduces correctly the main features of the wave field, i.e., general direction and period of the energy-carrying waves.

Thus, the synoptic situation prior to the formation of the killer wave on Feb. 1, 2003, was almost similar to the situation on Oct. 14, 2009, when, at the platform in Katsiveli, there were relatively frequently observed waves of the abnormal height. This gives grounds to assert that the scenarios of the formation of these killer waves were similar too.

\section{CONCLUSIONS}

This paper presents analysis of the field data collected in the Black Sea from the research platform in Katsiveli, in the autumn of 2009. The abnormally high waves, exceeding two times or more the significant wave height, were revealed in the data of wave staff array. It has been shown that the anomalously high waves are due to nonlinear processes in the wave field. The obtained relationship of the index of abnormality and kurtosis - the characteristics of the intensity of nonlinear processes, is in agreement with the previously published results [Shin and Hong, 2009]. Frequency of occurrence of the abnormally high waves (killer/freak/rogue waves) varies considerably on the time scale of several hours. In $90 \%$ of all cases, killer waves were observed in the swell wave system, whereas in $70 \%$ of all cases, the swell waves that formed killer waves propagated in approximately same direction as wind.

One of the fragments of the observations of higher occurrence frequency of the abnormally high waves (Oct. 14, 2009) was described in detail to identify the wind and wave conditions specific to the formation of 
killer waves. Evolution of the wave spectrum in this fragment was similar to that observed in the laboratory, where the formation of killer waves due to modulational instability was studied [Kuznetsov and Saprykina, 2009]. The data can be interpreted as the field observations of the energy cascade discrete in frequency and time, which is inherent in the development of modulational instability [Kartashova and Shugan, 2011].

From the analysis of the records on Oct. 14, 2009, the following scenario of the killer wave formation can be derived. Swell waves with a narrow spectrum (both in frequency and direction of propagation) are amplified in the conditions when wind direction is close to that of swell waves. Upon swell waves reaching the sufficient steepness, modulational instability develops, which leads to the formation of the abnormally high waves. This scenario agreed well with the reconstruction simulation of the wind and wave fields in the Black Sea, showing the background conditions of the storm on Oct. 14, 2009, in Katsiveli. A similar reconstruction was performed for Feb. 1, 2003, when a 12-meter killer wave was recorded with the Datawell wave buoy near Gelendzhik. These estimates have also supported the proposed scenario.

The findings of this study are supported by a number of results reported earlier. For example, in [Dotsenko, et al., 2009, 2010], the observations of killer-waves in the northwestern part of the Black Sea were described and it was concluded that frequency of occurrence of killer waves is distributed nonuniformely in time and is not explicitly linked with wind speed, its direction, and wave height. Figures 2 and 3, in [Dotsenko, et al., 2010], indicate that the abnormally high waves shown there were observed in the swell wave systems. Young [2006], analyzing data of the Datawell directional wave buoys offshore Australia, showed enhancing of swell waves due to wind of the same direction. Tamura, Waseda, and Miyazawa [2009] reconstructed wave conditions for the time of the accident in the Kuroshio region in 2008, when a fishing boat with 20 crewmembers sank because of an encounter with killer waves. Model calculations of the wave field have shown that swell waves existed in this region. These waves were intensified during interaction with wind waves that were propagating in approximately same direction. Thus, the scenario, which we proposed for the development of extremely hazardous situation, was also obtained in the paper of Tamura, Waseda and Miyazawa [2009].

Apparently, the scenario discussed is often realized in natural conditions. At least, it is possible to attribute $70 \%$ of the extremely high waves observed in our experiment to this scenario. If this is true, the operational monitoring of the wind-wave situations could serve as a basis for the killer wave forecast.

At this point, it is already possible to offer, based on this approach, the following simple practical strategy to risk assessment of a ship encounter with a killer wave in the Black Sea. The assessment is made for a given point $X$ and for a given time $T$ as follows:

1. Analysis of the wind-wave forecast several hours prior to the time $T$ is performed. It should be noted that the regional operational forecast of the wind situation over the Black Sea for three days, as well as the regional operational forecast of the wave situation for three days for a grid of $10 \mathrm{~km} \times 10 \mathrm{~km}$ is conducted consistently at the Department of AtmosphereOcean Interaction of $\mathrm{MHI}$. The results of the forecasts can be found at the site http://vao. hydrophys.org/ in the public domain. Because the real danger is associated with the waves of the height of several meters, reviewing the data allows identification of the zone of intensive storm. The corresponding wind field must also be characterized by storm wind speed. If, within the Black Sea region, there is a zone of intense storm, then the second step of the risk assessment is performed.

2. The purpose of this step is to determine whether swell waves will come from the 
storm zone to point $X$ at time $T$. In a real situation, instead of a single point, it is feasible to consider region $X$, chosen in accordance with the practical purposes of risk assessment. Fig. 16 explains how to perform this assessment. In this case, the forecast of the wave field shows that, in the storm zone, there are waves with period $\tau=$ $9 \mathrm{~s}$ (the wave period is presented by lengths of the small arrows). The large black arrow in Fig. 16 is drawn to connect the storm area with region $X$ in the direction that corresponds approximately to the direction of wave propagation. The length of this arrow is the distance $R$ that the waves must cover (itcan be determined, for example, by putting the arrow to the latitudinal axis; in Fig. 16, $R=110 \mathrm{~km}$ ). Time $t$, which is required for waves to travel this distance is determined by the formula $t=0.18 R / \tau$, where $R$ is expressed in $\mathrm{km}$, $\mathrm{T}$ is in seconds, $t$ is in hours (in our example, $t=2.2$ hours). If the waves reach region $X$ at time $T$, then the third step of the risk assessment is performed.
3. The purpose of this step is to determine whether swell waves will be amplified when approaching region $X$. For this puropose, the forecast of the wind field at time $T$ is reviewed. If, in and around $X$ at time $T$, a strong wind from the direction corresponding to the direction of the large black arrow is expected, there exists a real danger of encountering killer waves.

\section{ACKNOWLEDGEMENTS}

This work was performed under the joint project of the Russian Foundation for Basic Research (09-05-90430-Ukr-f-a) and the State Fund for Fundamental Research of Ukraine (F25/438) and has been partially supported by the EC FP7 ERC (Grant No. 227915 "Atmospheric planetary boundary layers - physics, modeling, and role in the Earth system") and by the State Agency for Science, Innovation, and Informatization of Ukraine (Contract M/412-2011).

\section{REFERENCES}

1. Annenkov S.Y., Shrira V. I. (2009) "Fast" Nonlinear Evolution in Wave Turbulence // Physical Review Letters Vol. 102. doi: 10.1103/PhysRevLett.102.024502, pp. 024502-1-024502-4.

2. Badulin S.I., Korotkevich A.O., Resio D., Zakharov V.E. (2009) Wave-wave interactions in wind-driven mixed seas // Proceedings of the Rogue Waves 2008 Workshop (October 13-15, 2008, Brest, France), pp. 77-86.

3. Chalikov D. (2007) Numerical simulation of the Benjamin-Feir instability and its consequences // Physics of Fluids 19, 016602, 15 p.

4. Divinskiy B.V., Kosyan R.D., Podymov I.S., Pushkarev O.V. (2003) Extreme wave in a northeast part of Black sea in February 2003 // Oceanology, Vol. 43, No 6, pp. 1-3 (in Russian).

5. Donelan M.A., Magnusson A.K. (2005) The role of meteorological focusing in generating rogue wave conditions / In: Proc. $14^{\text {th }}$ Aha Huliko'a Winter Workshop, Honolulu, Hawaii. pp. 139-145.

6. Dotsenko S.F., Ivanov V.A. (2006) Freak waves / Series "Modern problems of Oceanology», issue 1. MHI NAS of Ukraine, Sevastopol, 44 p. (in Russian).

7. Dotsenko S.F., Ivanov V.A., Poberezhny Yu.A. (2009) Freak waves in north-western part of the Black Sea // Dopovidi NAS of Ukraine, No 9, pp. 113-117 (in Russian). 
8. Dotsenko S.F., Ivanov V.A., Poberezhny Yu.A. (2010) Link of freak waves formation and meteorological conditions in north-western part of the Black Sea // Dopovidi NAS of Ukraine No 12, pp. 105-109 (in Russian).

9. Dudhia J. (1993) A nonhydrostatic version of the Penn State/NCAR mesoscale model: Validation tests and simulation of an Atlantic cyclone and cold front // Mon. Wea. Rev. Vol. 121, pp. 1493-1513.

10. Gramstad O., Trulsen K. (2010) Can swell increase the number of freak waves in a wind sea? // J. Fluid Mech. Vol. 650, pp 57-79.

11. Guedes Soares C., Cherneva Z., Antao E. M. (2004) Abnormal waves during Hurricane Camille // Journal of Geophysical Research. Vol. 109, C08008. doi:10.1029/2003JC002244, 7 p.

12. Hanson J.I., Phillips O.M. (1999) Wind Sea Growth and Dissipation in the Open Ocean // Journal of Physical Oceanography. Vol. 29. pp. 1633-1647.

13. Janssen P.A.E.M. (2003), Nonlinear four-wave interactions and freak waves // J. Phys. Oceanogr. Vol. 33, pp. 863-884.

14. Kartashova E., Shugan I.V. (2011) Dynamical cascade generation as a basic mechanism of Benjamin-Feir instability // EPL (Europhysics Letters) Vol. 95, No 3, 30003, doi:10.1209/02955075/95/30003, 6 p.

15. Kharif C., Pelinovsky E., Slunyaev A. (2009) Rogue waves in the ocean. Springer-Verlag, Berlin, Heidelberg, 216 p.

16. Komen G., Cavaleri L., Donelan M., Hasselmann K., Hasselmann S., Janssen P.A.E.M. (1994) Dynamics and Modelling of Ocean Waves. Cambridge University Press, $532 \mathrm{p}$.

17. Kurkin A.A., Pelinovsky E.N. (2004) Freak waves: facts, theory and modelling. NNSTU, Nizhny Novgorod, 158 p. (In Russian).

18. Kuznetsov S.Yu., Ya.V. Saprykina, R.D. Kos'yan, O.V. Pushkarev (2006) Formation Mechanism of Extreme Storm Waves in the Black Sea // Doklady Earth Sciences, Vol. 408, No 4, pp. 570-574.

19. Kuznetsov S., Saprykina Y. (2009) Fine structure and peculiarities of wave spectra with Benjamin - Feir instability // Proceedings of the Rogue Waves 2008 Workshop, October 13-15, 2008, Brest, France. pp. 99-108.

20. Kuznetsov S.Yu., Dulov V.A., Saprykina Ya.V., Dotsenko S.F., Malinovsky V.V., Polnikov V.G., Shokurov M.V. (2011) Extremely dangerous storm conditions in the Black Sea / Series "Modern problems of Oceanology", issue 9. MHI NAS of Ukraine, Sevastopol. 66 p. (in Russian).

21. Liu P.C., Pinho U.F. (2004) Freak waves - more frequent than rare! // Annales Geophysicae Vol. 22. pp. 1839-1842.

22. Mori N., Janssen, P. A. E. M. (2006) On kurtosis and occurrence probability of freak waves // J. Phys. Oceanogr. Vol. 36, pp. 1471-1483. 
23. Onorato, M., Osborne, A.R., Serio, M., Damiani, T. (2001) Occurrence of freak waves from envelope equations in random ocean wave simulations. / Proceedings of the workshop "Rogue Waves 2000". IFREMER, Brest. pp. 181-191.

24. Onorato M., Cavaleri L., Fouques S., Gramstad O., Janssen P.A.E. M., Monbaliu J., Osborne A.R., Pakozdi C., Serio M., Stansberg C.T., Toffoli A., Trulsen K. (2009) Statistical properties of mechanically generated surface gravity waves: a laboratory experiment in a threedimensional wave basin // J. Fluid Mech. Vol. 627, pp. 235-257.

25. Osborne A.R., Onorato M., Serio M. (2005) Nonlinear Fourier analysis of deep-water, random surface waves: theoretical formulation and experimental observations of rogue waves / In: Proc. 14 ${ }^{\text {th }}$ Aha Huliko'a Winter Workshop, Honolulu, Hawaii, pp. 65-77.

26. Phillips O.M. (1985) Spectral and statistical properties of the equilibrium range in windgenerated gravity waves // Journal of Fluid Mechanics. Vol. 156. pp. 505-531.

27. Saprykina Ya.V., Dulov V.A., Kuznetsov S.Yu., Smolov V.E. (2010) Freak waves in the Black Sea: mechanisms and conditions of occurrence // Ecological safety of coastal and shelf zones and comprehensive use of shelf resources. Vol. 21. MHI NAS of Ukraine, Sevastopol pp. 88-102 (In Russian).

28. Socquet-Juglard H., Dysthe K., Trulsen H. E., Krogstad J. Liu (2005) Distribution of surface gravity waves during spectral changes // J. Fluid Mech., Vol. 542, pp. 195-216.

29. Shin S., Hong K. (2009) Nonlinear Parameters of Wave Distribution to Characterize Freak Waves // Proceedings of the Rogue Waves 2008 Workshop (October 13-15, 2008, Brest, France) pp. 157-158.

30. Tamura H., Waseda T., Miyazawa Y. (2009) Freakish sea state and swell-windsea coupling: Numerical study of the Suwa-Maru incident // Geophysical Research Letters, Vol. 36, L01607, doi:10.1029/2008GL036280. 5 p.

31. The WAMDI group (1998) The WAM model. - The third generation ocean wave prediction model. // J. Phys. Oceanography., Vol. 18, pp. 1775-1810.

32. Yefimov V.V., Komarovskaya O.I., Shokurov M.V. (1998) Numerical model for wind waves in the Black Sea. / Preprint MHI NAS of Ukraine, 40 p. (in Russian).

33. Young I.R. (1994) On the measurement of directional wave spectra // Applied Ocean Research. Vol. 16, pp. 283-294.

34. Young I.R. (2006) Directional spectra of hurricane wind waves // Journal Geophysics Research. Vol. 111, C08020, doi:10.1029/2006JC003540, 14 p.

35. Zakharov V.E., Dyachenko A.I., Prokofiev A.O. (2008) Freak Waves: Peculiarities of Numerical Simulations / In "Extreme Ocean Waves", Eds. E. Pelinovsky, C. Kharif, Springer. pp. 1-30. 


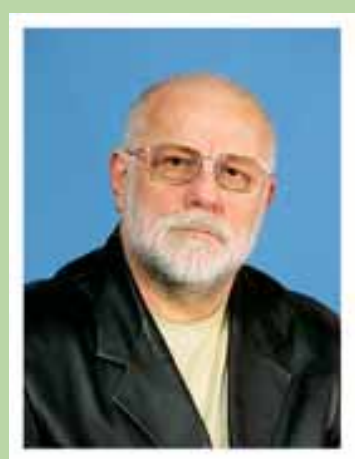

Vitaliy A. Ivanov, Dr.Sc., Professor (hydrophysics), is Academician of the National Academy of Sciences of Ukraine. He is Director of Marine Hydrophysical Institute (MHI) (Sevastopol, Ukraine), Research Director of the Sevastopol Branch of M.V. Lomonosov Moscow State University, Director of Instrument Designing \& Engineering Bureau of $\mathrm{MHI}$, and Head of Shelf Hydrophysics Department of $\mathrm{MHI}$. His activities include research in hydrophysics of the sea shelf with the focus on sea currents, long-wave processes, ecology of the environment, and development of marine resources. He is the author and co-author of over 350 scientific publications including books and textbooks; the most recent of them is "Oceanography of the Black Sea" (2011).

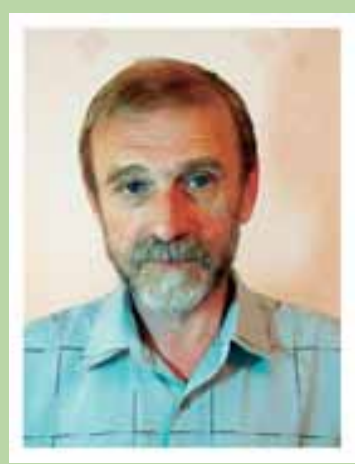

Vladimir A. Dulov, Dr.Sc., is Research Leader of the Laboratory of Applied Physics of the Sea at MHI. He has been involved in the field studies of the sea since 1979 after graduating from Moscow Physical Technical Institute. His activities include research on wind waves with the focus on wave breaking and nonlinear interactions of waves, remote sensing of the sea, turbulent boundary layers near the sea surface. He is the author and coauthor of about 100 scientific publications.

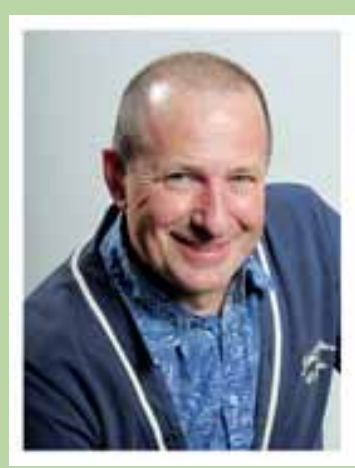

Sergey Yu. Kuznetsov, Dr.Sc., is Head of Laboratory at the Institute of Oceanology of the Russian Academy of Sciences, Moscow. He specializes in experimental research of coastal zone dynamics, nonlinear waves, wave breaking, suspended sediments, and sediment transport. He is the author and co-author of about 100 scientific publications.

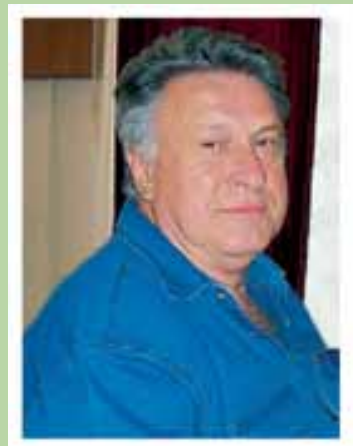

Sergey F. Dotsenko, Dr.Sc., is Professor, and Principal Research Scientist at MHI. His scientific interests cover surface and internal waves in the ocean; seiches, rings, and fronts dynamics; tsunami generation and propagation; and numerical modeling of the shallow-water processes in the Black, Azov, and Caspian Seas. He is the author and co-author of 275 scientific publications. 


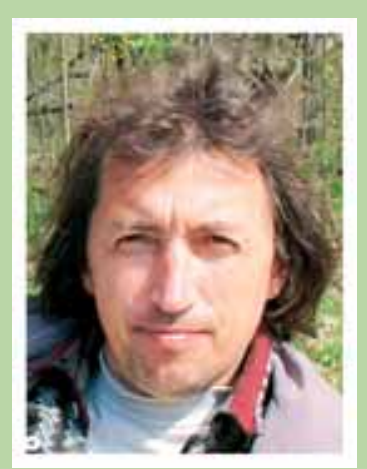

Mikhail V. Shokurov, Dr.Sc., is Leading Scientist of the Atmosphere-Ocean Interaction Department at $\mathrm{MHI}$. The focus of his research is in numerical modeling of the mesoscale atmospheric processes over the sea. He is the author of more than 65 scientific publications.

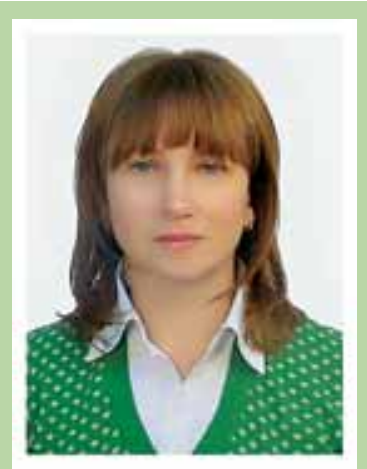

Yana V. Saprykina, Ph. D., is Senior Researcher at Shelf and Sea Coasts Laboratory of P.P. Shirshov Institute of Oceanology of the Russian Academy of Sciences, Moscow. She is expert in experimental investigations of nonlinear waves, in mathematical modeling of nonlinear waves, and in methods of analysis of nonlinear and non-stationary data. She is the author and coauthor of more than 60 scientific publications.

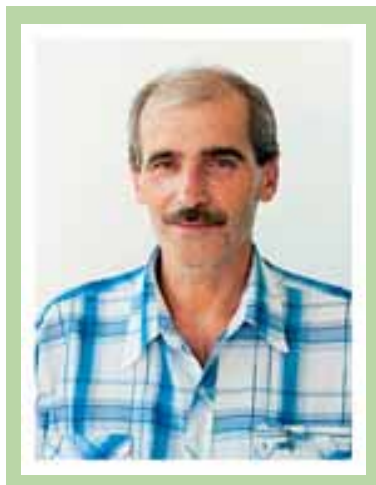

Vladimir V. Malinovsky, Dr.Sc., is Senior Researcher of Remote Sensing Department at MHI. He has been employed at MHI since 1978 and he has more than thirty years of experience in experimental studies of the sea surface, processing of satellite images, analysis of SAR data, and application of the radar data to retrieve the wind field over sea, temperature fronts, and surface wave parameters. He is the author of more than 80 scientific publications.

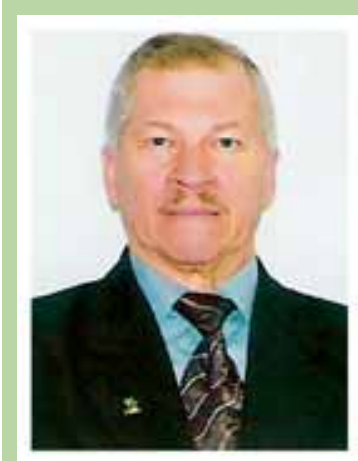

Vladislav G. Polnikov, Dr.Sc., is Leading Scientist of Air-Sea Interaction Department of Obukhov Institute of Atmospheric Physics of Russian Academy of Sciences, Moscow. His main interest is in the nonlinear features of stochastic waves on water, wind wave statistics, and numerical modeling. He is the author of two monographs and of about 150 papers, a member of the international WISE group, and a member of the Editorial Board of the "Marine Science" journal (Scientific and Academic Publishing, USA). 